\title{
فاعلية استخدام إستراتيجية اليد المفكرة في تنمية بعض المهارات الفنية لدى طلاب الصف الأول الثانوي المعاقين بصرياً
}

إعلداد

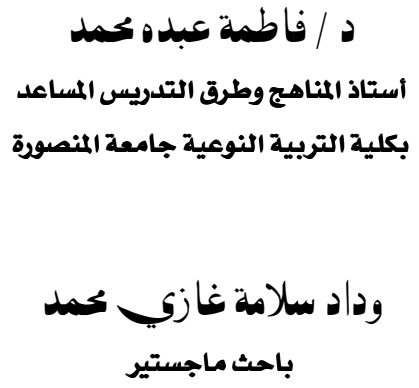

مجلة بحوث التربية النوعية ـ جامعة المنصورة

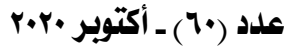




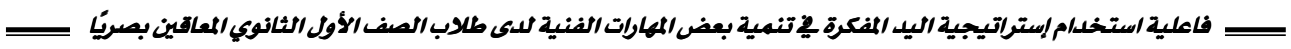


مجلة بحوث التربية النوعية - علدد •r.r. - م أكتوبر

\title{
فاعلية استخدام إستراتيجية اليد المفكرة في تنهية بعض المهارات الفنية لدى طلاب الصف الأول الثانوي المعاقين بصرياً
}

\author{
(إعداد \\ د* / فاطمة عبدهمحمد

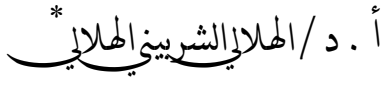 \\ وداد سلامةغازي محمد \\ د/***مس السيد عوض
}

همقدهة:

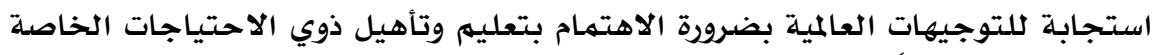

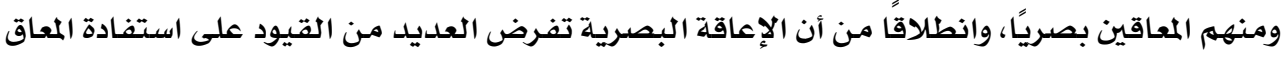

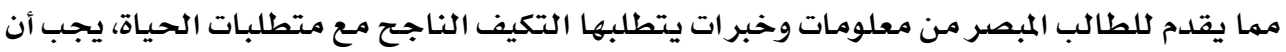

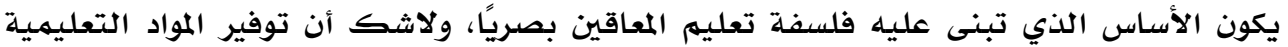

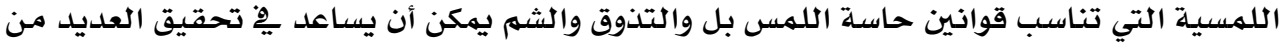

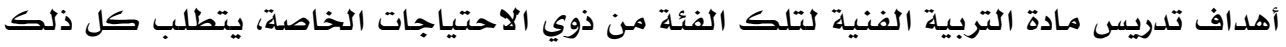

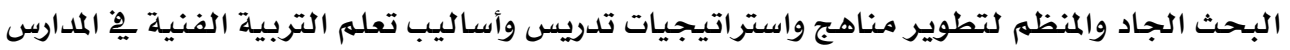

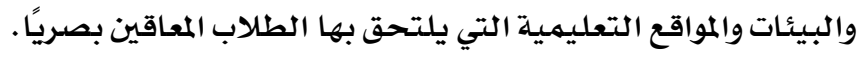
ويشهد البحث العلمي التربوي التجريبي الكثير من التطوير وفقا لهذا التوجه مهما ساهم

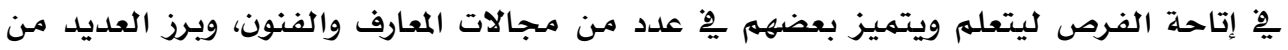

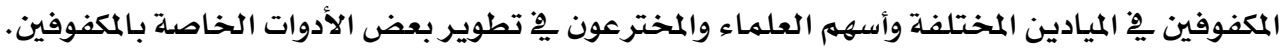

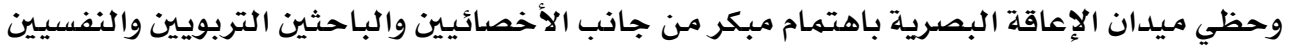

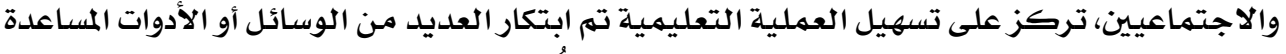

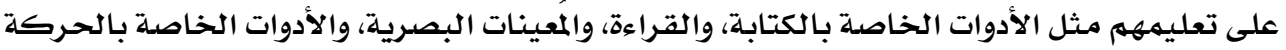

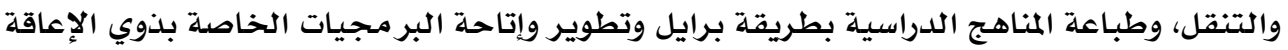

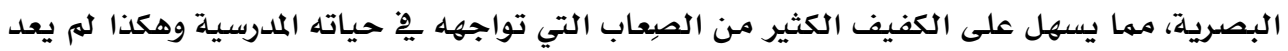

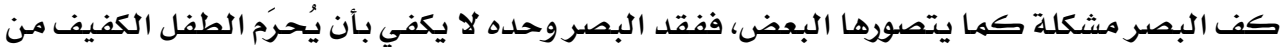
أن يحيا حياة عادية كبقية الأطفال الآخرين (Carroll, 1961).

" أستاذ التخطيط التربوي والإدارة التربويه بكلية التربية النوعية ووزير التربية والتعليه والتعليم الفنى السابق " * أستاذ المناهج وطرق التدريس المساعد بكلية التربية النوعية جامعة المنصورة ** مدرس الأثغال الفنية والشعبية (أشغال المعادن) بكلية التربية النوعية جامعة المنصورة باحث ماجستير 


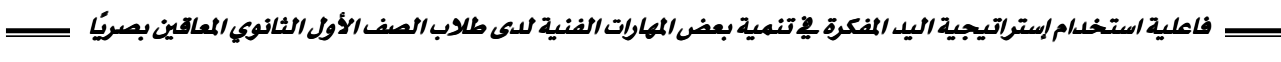
تشير الدراسات التشخيصية إلى تباين حالات ودرجات الإصابة بالإعاقة البصرية لنرصد

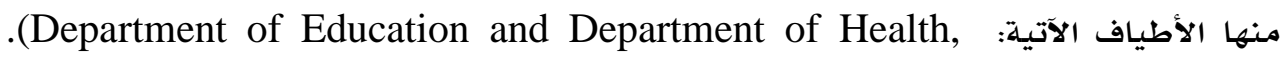
2015)

1- العمى التام: الأشخاص الذين ليس لديهم وظيفة بصرية، أي ليس لديهم إدراك للضوء وهم

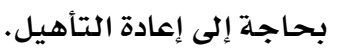

r- ضعف البصر: مجموعة ضعف البصر الشديد - الأشخاص الذين يعانون من حدة بصر rا

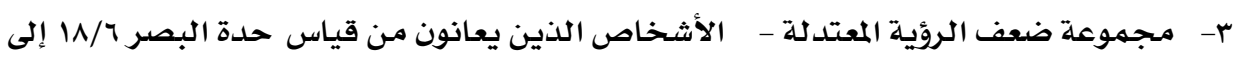

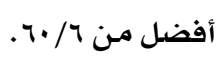

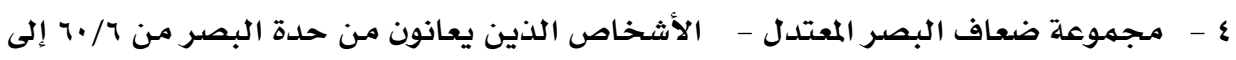

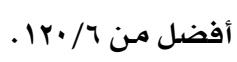

ويشكل هذا التباين تحديات جمة لأطراف العملية التربوية بكافة مراحلها ونظم التصميم

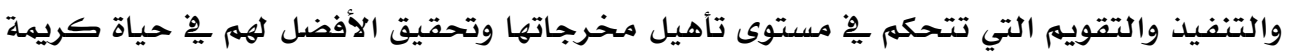

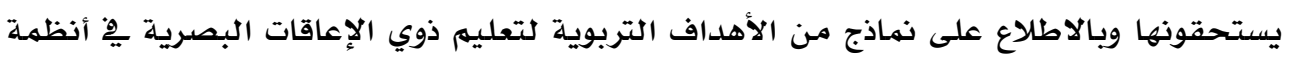

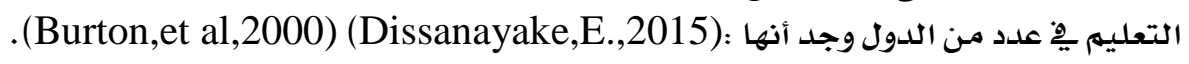

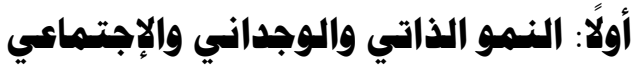

$$
\text { (r) (1) تنمية الإمكانات الجسدية والعقلية والاجتماعية لهؤلاء الطلاب إلى أقصى حد. }
$$

(r) تطوير مهارات التكيف مـع الحياة ومهارات الرعاية الذاتية لدىههم حتى يصبحوا الفراداً

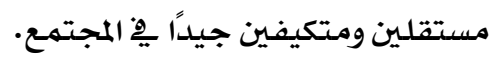

\section{ثانياً: النسمو المهرفي والأكادبيمي}

(1) تطوير المهارات الأكاديمية والوظيفية بتعلهم المواد الأكاديمية والثقافية، والمهارات التقنية

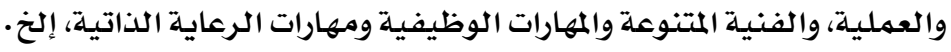

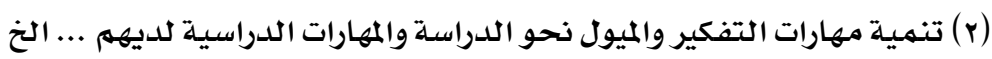

وعلى الرغم من إهتمام أنظمة التعليم بالتأكيد على استهداف النمو الشامل لفئات

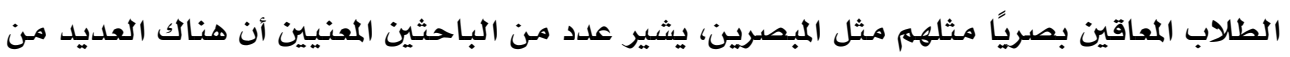

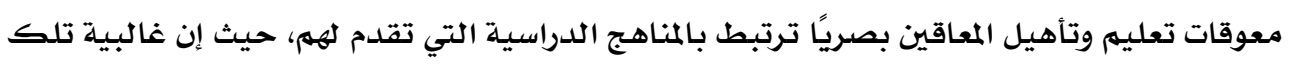

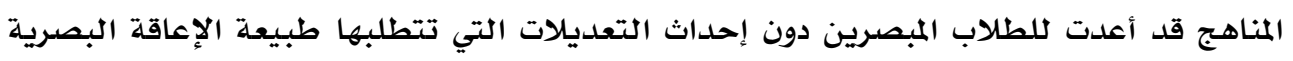

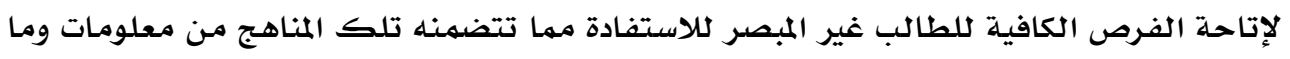
توفره من فرص لإكتسابه العديد من المهارات والاتجاهات وغيرها من أوجه التعلهم التي تؤهله

\section{Yo7}


مجلة بحوث التربية النوعية - علدد •r.r. - م أكتوير

للتكيف مـع ظروف إعاقته ومـع متطلبات الحياة يِّ مجتمـع المبصرين، هذا بالإضافة إلى افتقار مدارس

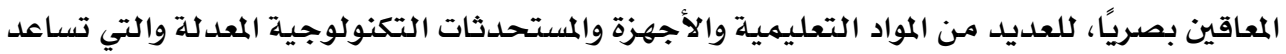

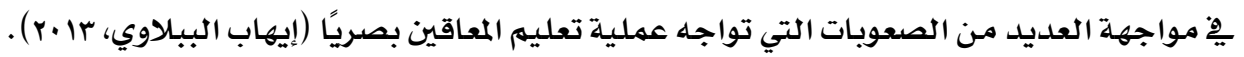

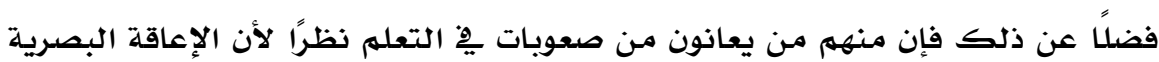

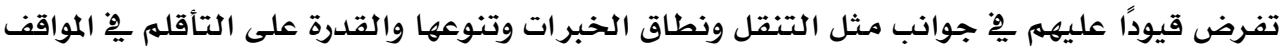
المختلفة، وقد يواجهون صعوبات التعلهم التالية: (Lalit Dandona, et al, 2006).

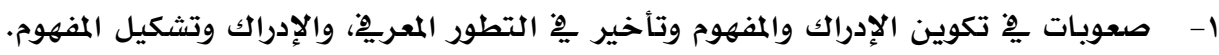

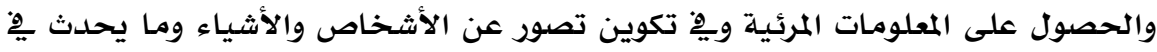
بيئتهم.

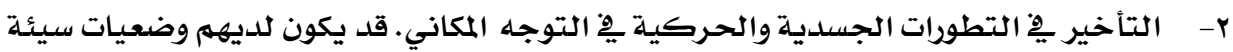
وضعف تحكم اليد قد يصطدمون بسهولة بالأثاث والمعدات والأشخاص. r- مشاكل بِ التطورات الاجتماعية والعاطفية.

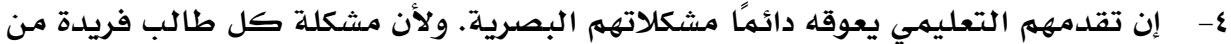
نوعها، فإن استراتيجيات التعامل مـع المشكلات تكون فردية للغاية. ه- إن تعلمهم يكون بطيئًا أيضًا وفترة انتباههم قصيرة. قد يحتاجون إلى مزيد من الوقت

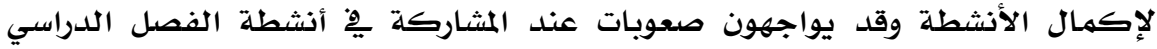

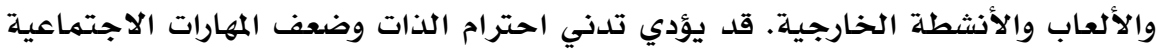

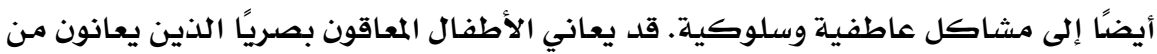

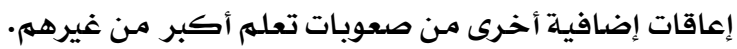
وبالنظر إلى دور التربية الفنية وممارسة أنشطتها من قبل أطياف الطلاب تشير معطيات

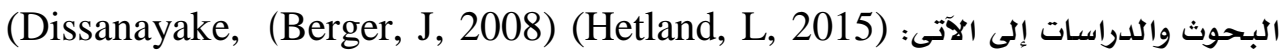
.E., 2015) ( Burton, et al, 2000) (Fiskke, E., 1999) ا- إن فوائد التعليه الفني للأشخاص المكفوفين أو ضعاف البصر هي نفسها إلى حد كبير

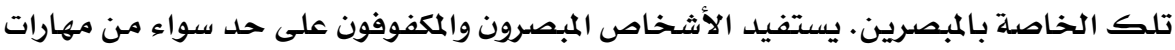

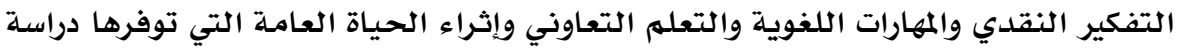
تاريخ الفن. r- ب يمكن أن تعمل صناعة الفن على تعزيز الوعي الحسي والبر اعة اليدوية والثقة بالنفس والوعي الذاتي.

ب- يستفيد الأطفال من جميع الأعمار من المناهج الأكاديمية المعززة بتدريس علم الجمال

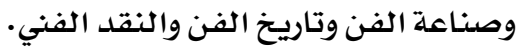


ع- بين المزايا الفريدة كلأفراد المكفوفين هي مهارات القراءة بطريقة برايل، ومهارات التنقل

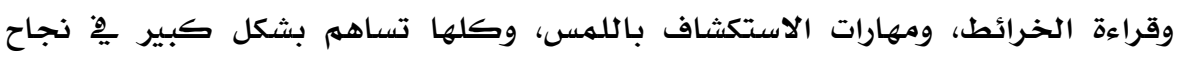

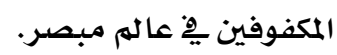
ه- إن الإلمام بالثقافة المرئية والمساهمهة فيها يساعد المكفوفين على اختراق الحواجز الاجتماعية وزيادة الثقة بالنفس وبالآخرين.

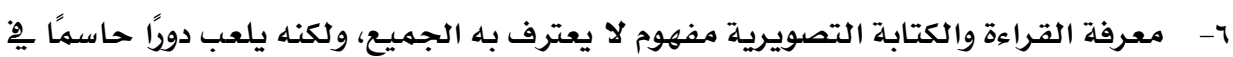
الحياة اليومية للمعاقين بصريًا. V- إن تدريب الطلاب على تطوير مهارات الاستكشاف باللمس وتدعيم توظيفهم للحواس

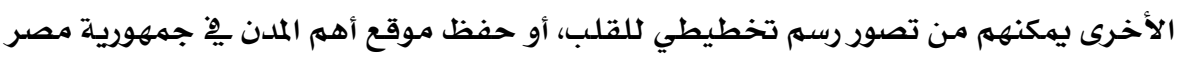

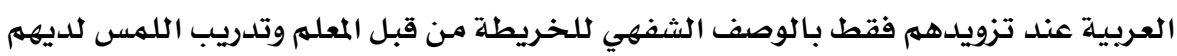

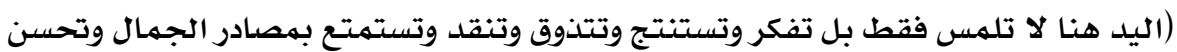

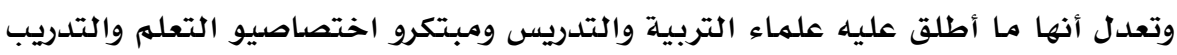

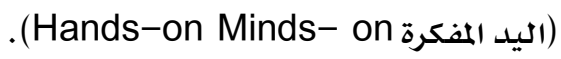
1- يمكن للأشخاص ضعاف البصر الوصول إلى ثروة من المعلومات التصويرية وفهم المعلومات

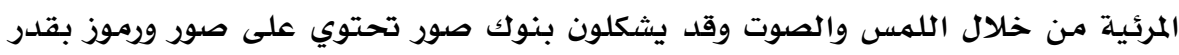

$$
\text { خبر اتهم مِّ مجال التربية الفنية. }
$$

إنَّ أسس تخطيط وبناء المناهج سواء كانت للمبصرين أو المكفوفين وضعاف البصر لأبد أن

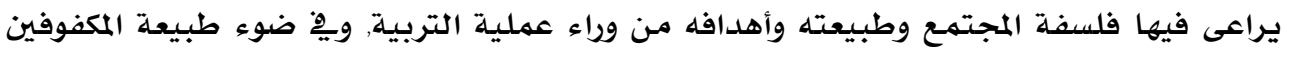

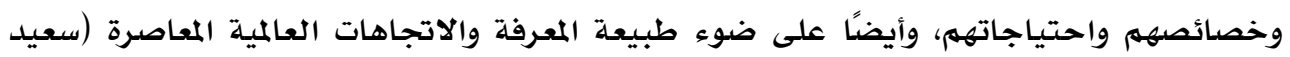

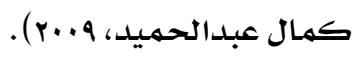

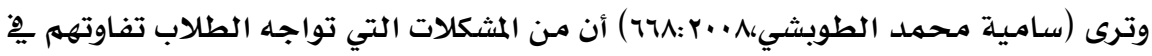

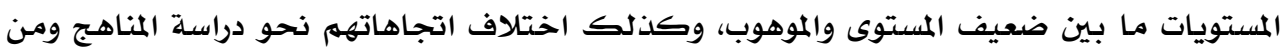

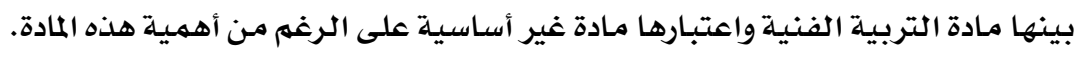

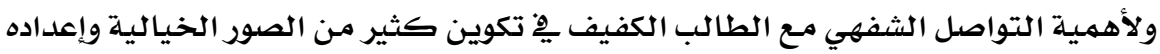

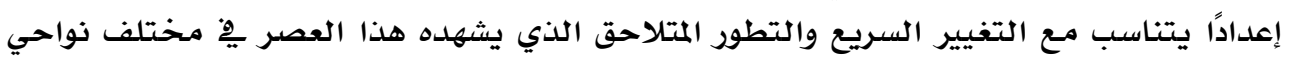

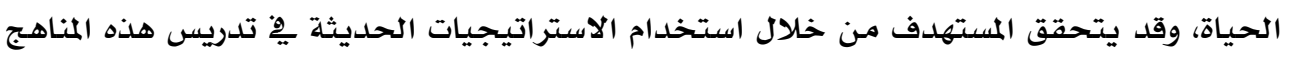

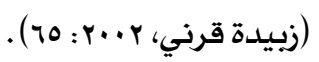

وبناء على مـا تقدم حرصت الباحثة على محاولة الإسهام بـالبحث ِِّْ مجال تفعيل استفادة

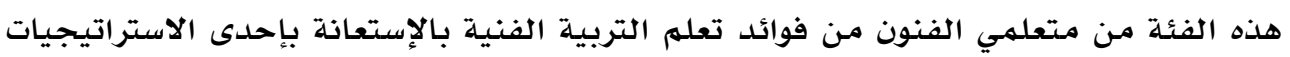

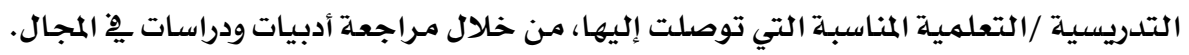


وبناء على ما تقدم يهدف البحث الحالي إلى التعرف علي فاعلية الاستعانة باستراتيجية

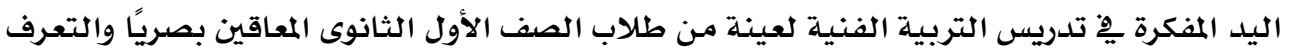

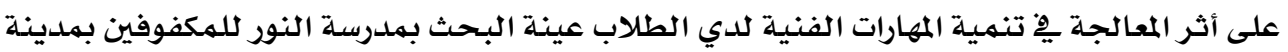
المنصورة - محافظة الدقهلية.

وتركز بعض خطوات الإستراتيجية على التوظيف الذكى لحاسة اللهس. وتعد حاسلة

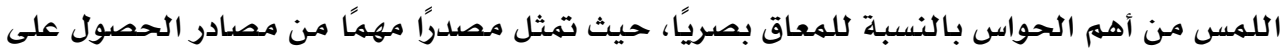

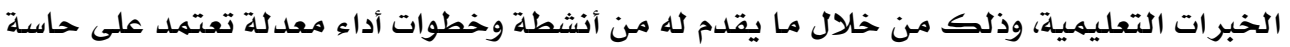

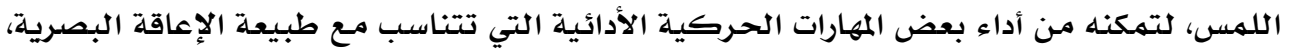

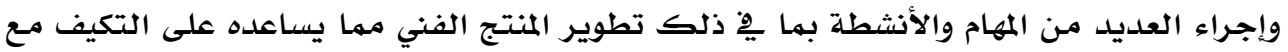

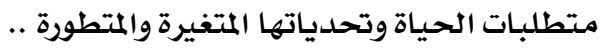

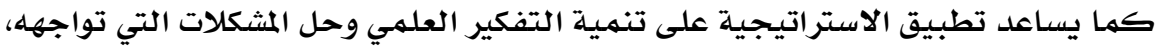

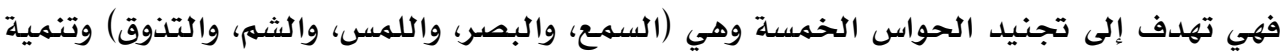

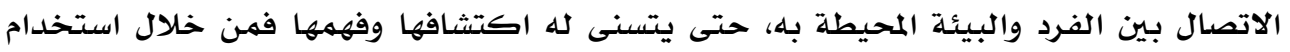

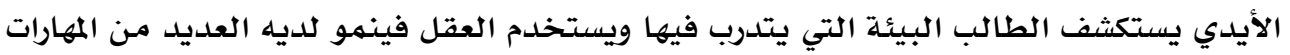

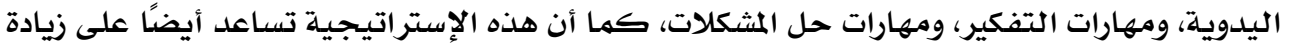

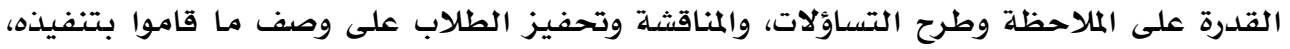

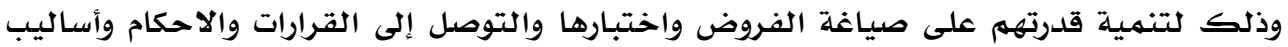

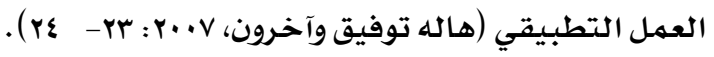
وهذه الإستراتيجية تُعد ضمن مشروع أجرى يِّ فرنسا وقد أطلق عليها "اليد ِِِ العجين"

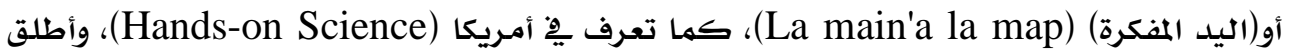

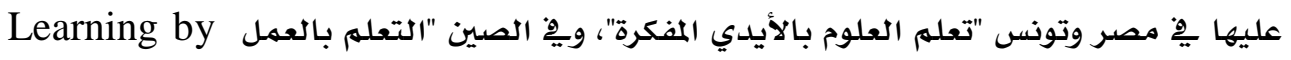

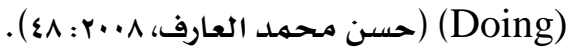
من خلال إجراء دراسات استطلاعية تضمنت زيارات ميدانية لعدد مـن مدارس المكفوفين

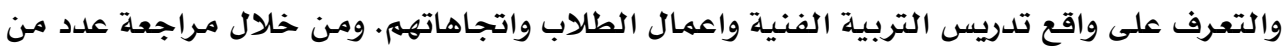

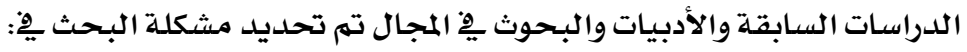
ا- تدني مستوى الاهتمام بتدريس المادة وممارسة الطلاب لأنشطتها ومن ثم ضعف إدراكهم

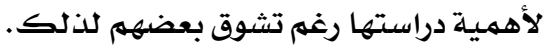
r- عدم توفر منهج خاص لهذه الفئة يتلاءم مـع ظروفهم ومشكلاتهم. r- عدم امتلاك معظمهم للههارات الأساسية يِّ مجال التربية الفنيلة.

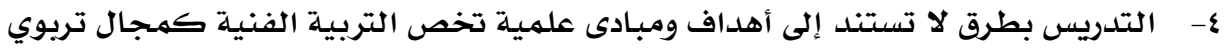

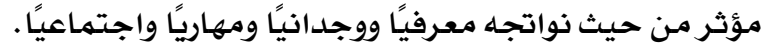



ه- تجاهل مهارسات التدريس الحالية للاحتياجـات الخاصسة لهذه الفئة رغم مـا يهكن أن تسهم بـه مهارسـة الطلاب للفنون من تأثيرات إيجابية على حياتهم. 7- ومن ثم برزت أهميـة الدراسـة العلميـة المنهجيـة لهذه المشكلة والتعرف على تأثيرها والبحث عن حلول لها وتطبيق إحلى استراتيحيات التدريس/ التعلهم الأكثر فاعلية يِّ الاستجابة لاحتياجات الطلاب عينـة البحثث وتحقيق أهدافهم من مهارسـة أنشطتها.

وبناءًا على مـا تقدم تتحدد مشكلة البـحث ِِّ محاولة الإجابة عن التساؤل الآتي: ما فاعلية استخدام استراتيجية اليد المفكرة مِ تنمية بعض المهارات الفنية للدي طلاب

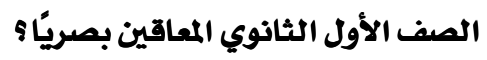
ويتفرع من هذا التسـاؤل الأسئلة الآتية: ا- كيف يهكن تطبيق استراتيجية اليد المفكرة يغ تصميم وتنفيذ دروس التربية الفنية لطلاب الصف الأول الثانوي المعاقين بصريًا ؟ ץ- مـا فاعلية استراتيجية اليد المفكرة فِ تنمية تحصيل الجوانب المعرفية للمهارات الفنية لدى طلاب الصف الأول الثانوي المعاقين بصريًا r- مـا فاعلية استراتيجية اليد المفكرة فِ تنهية المهارات الفنية لدى طلاب الصف الأول الثانوي

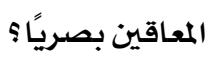
أهد|ف البحث

$$
\text { تتحدد أهداف البـحث الحالي فيما يلي: }
$$

ا- التعرف على كيفية تطبيق استراتيجية اليد المفكرة يخ تصميهم وتنفيذ دروس التربية الفنية لدى طلاب الصف الأول الثانوي المعاقين بصريًا وتصميهم دليل معلم متكامل بناء على ذلك.

ץ- التعرف على فاعلية استراتيجية اليد المفكرة يف تنمية تحصيل الجوانب المعرفية للههارات الفنية لدى طلاب الصف الأول الثانوي المعاقين بصريًا. ب- التعرف على فاعلية استراتيجية اليد المفكرة فِ تنميـة الجوانب الأدائية للمهارات الفنية لدى طلاب الصف الأول الثانوي المعاقين بصريًا.

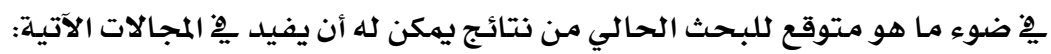
ا- إلقاء الضوء على ضرورة الاهتمام باستخدام استراتيجيات ووسائل تعليميلة تتناسب مـع

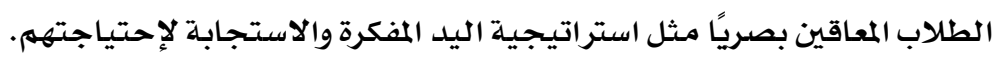


مجلة بحوث التربية النوعية - علدد •r.r. - م أكتوبر

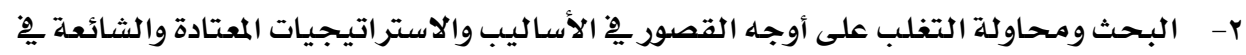
ممارسة التدريس بمدارس المعاقين بصريًا.

ب- إبراز الجوانب البناءة لتعلم المهارات الفنية لتنمية الاتجاهات الإيجابية نحو الممارسات

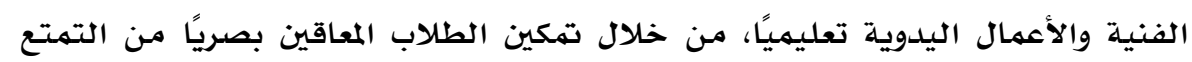
بممارسسة الأنشطة الفنية. ع- إلقاء الضوء على أهمية إكتساب الجوانب المعرفية للههارات الفنية وتنمية التفكير ِِّ إتمام وإتقان المهمهة الفنيـة. ه- تطوير أنشطة وخبر ات متنوعة تستثمر طاقات وقدرات وحواس الطلاب المعاقين بصريًا يِّة تعلهم ومهمارسة الأنشطة الفنية اليدوية. منههج البمث

تعتمد الباحثة يِ الدراسة الحالية على استخدام المنهجين التاليين: ا- المنهج الوصفي التحليلي: تحديد قائمة بالمجالات والموضوعات والمهارات الفنية التي تتفق

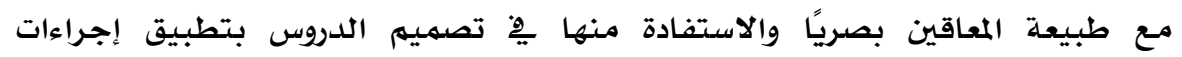
الإستر اتيجية المقترحة. r- المنهج التجريبي: الذي يشتمل على المتغيرات التالية:

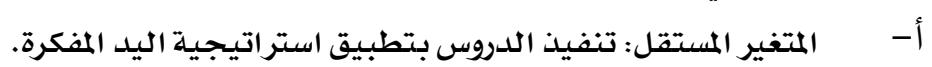

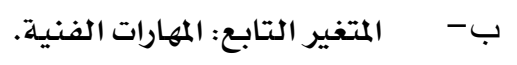

\section{المدود البحثية}

$$
\text { يقتصر البحث الحالي على الآتي: }
$$

ا- عينة البحث: عينة من طلاب الصف الأول يِّ المرحلة الثانوية بمدرسة النور للمكفوفين

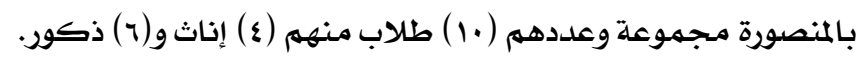

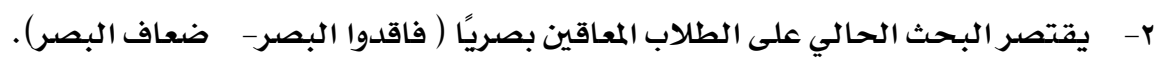

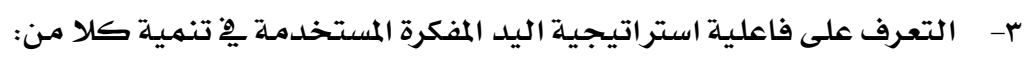

$$
\begin{aligned}
& \text { أ- الجوانب المعرفية للدروس. } \\
& \text { ب- عدد من المهارات الفنية المحلددة. }
\end{aligned}
$$

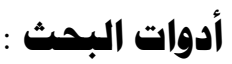

$$
\begin{aligned}
& \text { 1- اختبار تحصيلي لقياس الجانب المعريٌ للههارات (إعداد الباحثة). } \\
& \text { r- بطاقة ملاحظة لقياس الجانب الأدائي للمهارات (إعداد الباحثة). }
\end{aligned}
$$




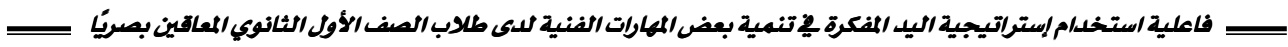
ويوضح الشكل التادي التصميم التجريبي للبحث الحالي:

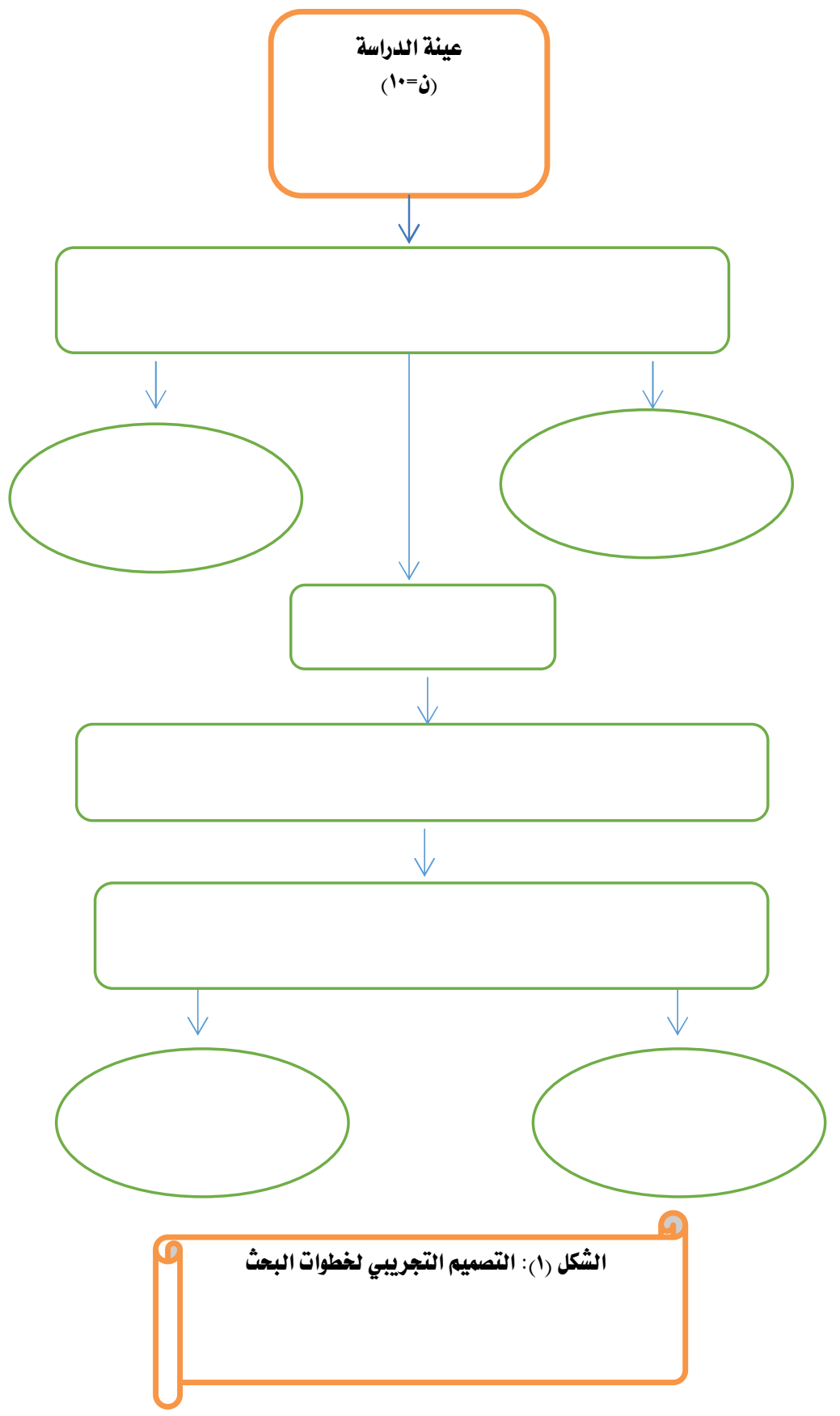




\section{الإسمات البمثينة:}

\section{الإعاقة البصرية (Visual Impairment)؛}

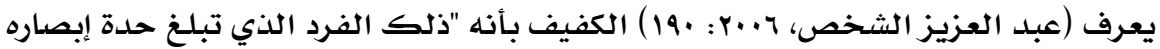

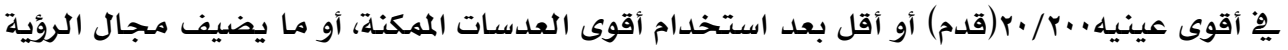

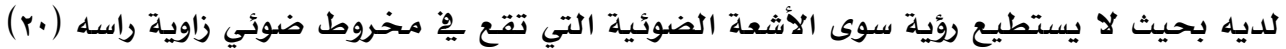

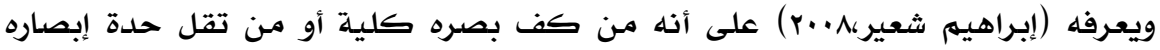

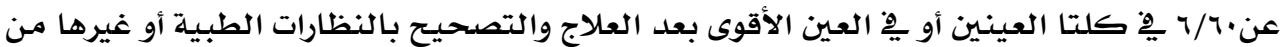

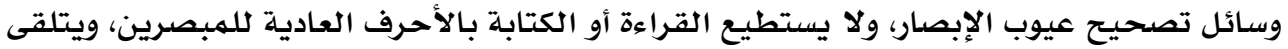

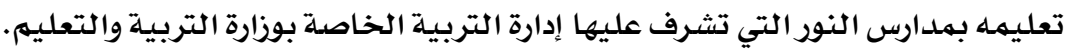

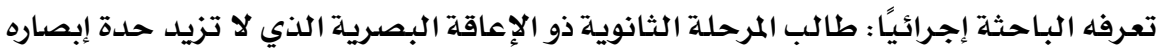

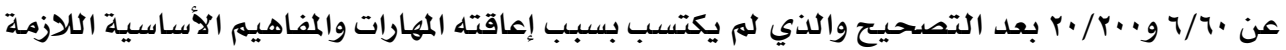

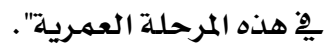
المهارات الفنية (Artistic skills)؛

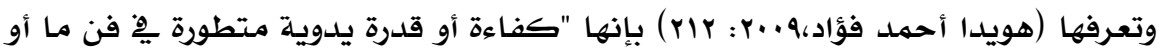

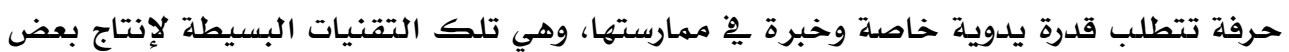

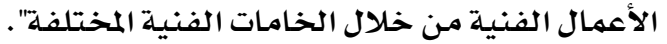

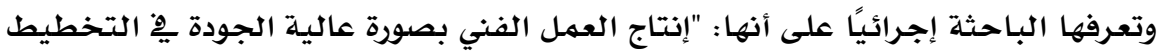

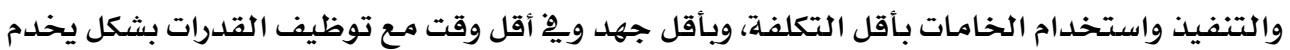

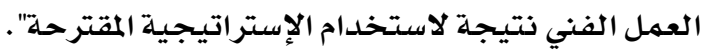

\section{إجراsات البحث}

ا- الاطلاع على الأدبيات والدراسات السابقة المتعلقة بمتغيرات البحث والاستفادة منها ِي2

$$
\begin{aligned}
& \text { مجال البحثث الحالي. }
\end{aligned}
$$

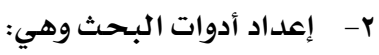

$$
\begin{aligned}
& \text { " إعداد اختبار تحصيلي لقياس الجانب المعريٍ للمهارات الفنية. } \\
& \text { • إعداد بطاقة ملاحظة لقياس الجانب الأدائي للمهارات. } \\
& \text { r- ب- عرض أدوات البحث على مجموعة من المحكمـين وتعديلها. } \\
& \text { ع- إعداد أدوات البحث ِِّ صورتها النهائية. }
\end{aligned}
$$

ه- تحديد عينة البحث مجموعة واحدة تجريبية نظرًا لقلة عدد الطلاب. 


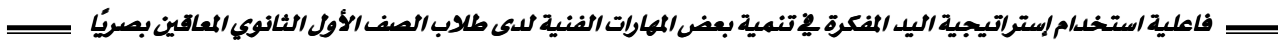
7- إجراء دراسـة استطلاعية على عينة من طلاب الصف الأول الثانوى المعاقين بصريًا وعددهم

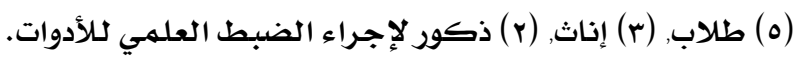

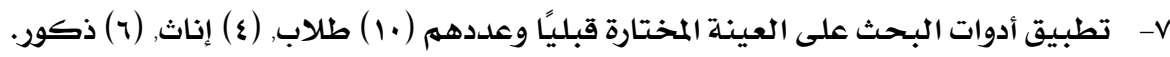
1- - تدريب طلاب المجموعة التجريبية على المهارات الفنية بتطبيق استر اتيجية اليد المفكرة. 9- تطبيق أدوات الدراسلة على العينـة المختارة بعديًا وعددهم ( • ) طلاب, (ع ) إناث, ( ) ذكور. • - رصد البيانات الناتجـة عن التطبيق القبلي والبعدي. 11 - المعالجة الإحصائيـة للبيانات بالأساليب الإحصائيـة المناسبـة. r ا - تحليل النتائج وتفسيرها. rا - تقديهم التوصيات ِِِ ضوء نتائَج الدراسـة. الدراسات السابقة اللدراسات الخاصة بالمحور الأول: تتضمن الدراسات التي توفرت للعرض مِّه هذا القسهم من البحث عددًا من الدراسـات التي

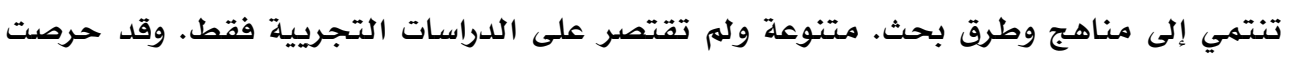

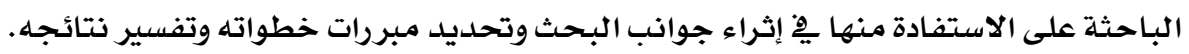
دراسات تتناولت استراتيجية اليد المفكرة: 1)- دراسة "نجلاء محمود يوسف:r|r.r" بعنوان "فعالية استخدام استراتيجية اليد المفكرة لتنمية المفاهيم العلمية وبعض المهارات العلمية لدى التلاميذ المكفوفين بالمرحلة الإعدادية".

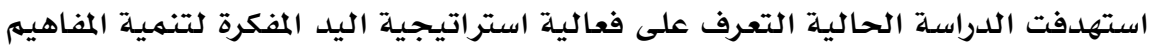

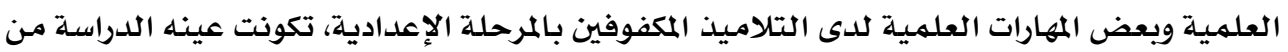

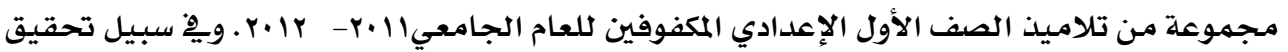

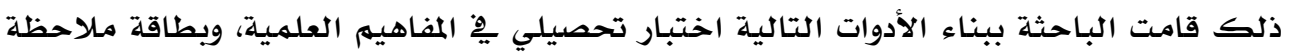

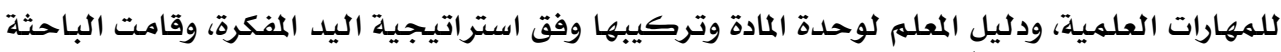

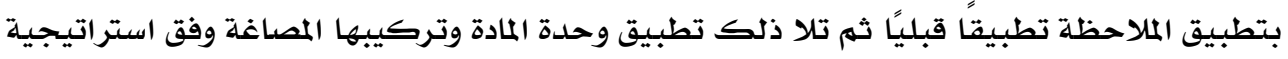

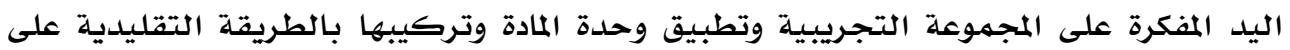
المجموعة الضابطة، ثم التطبيق البعدي لكلاختبار وبطاقه الملاحظة. What K-8 Principals Know About " دراسة " Jerquenson, 2005 Hands- on Science وهدفت إلى الكثف عن نتائج التقارير النادرة التي أجريت لأكثر من ·ـ ·ـ عامًا لتحديد

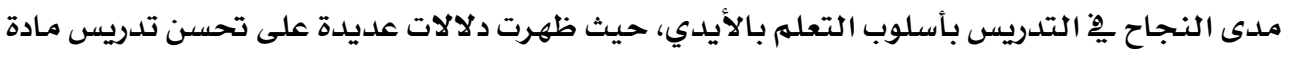

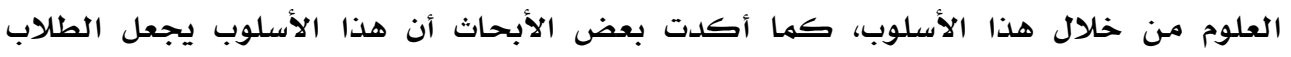


مجلة بحوث التربية النوعية- علدد •r - أكتوير م.r.

يستخدمون قوتي اليد والعقل Hands on \& Minds on، وذلك لأنها تحقق الاهتمام والاستمتاع حيث يساعدهم ذلك النوع على تطبيق المفاهيم العلمية بحيث يصبحون أكثر قدرة على مواجهة المهل

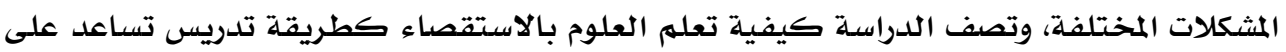
ظهور الطاقات الذهنية داخل كل فرد. r) دراسة "تامر على عبداللطيف: 17 إץ" بعنوان "إستخدام إستراتيجية اليد المفكرة لتصويب بعض التصورات البديلة وتنمية بعض عمليات العلم لدى تلاميذ المرحلة الإبتدائية".

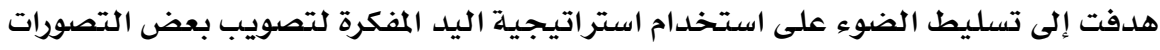

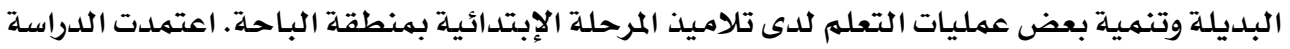

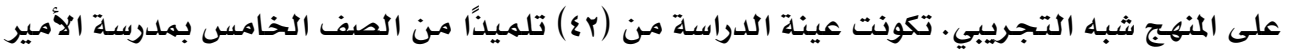

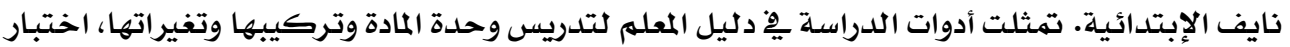

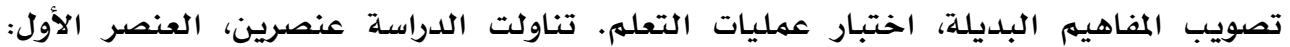

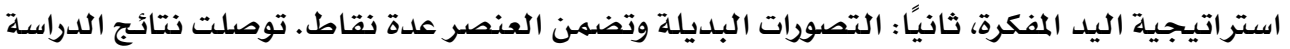

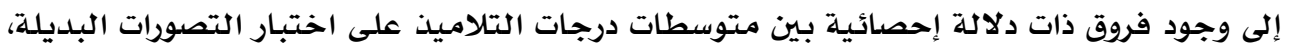

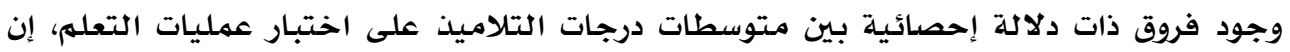

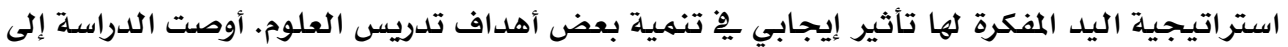

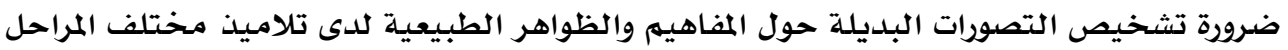

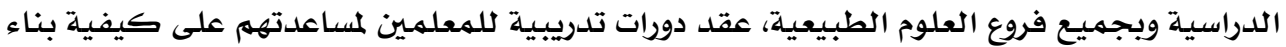

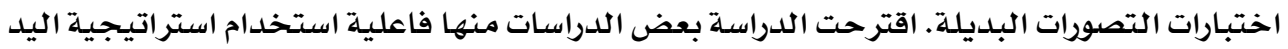

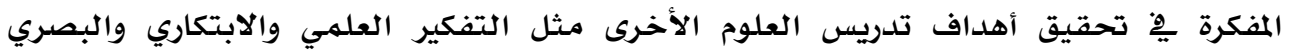
والاستقصاء لدى تلاميذ المرحلة الإبتدائية.

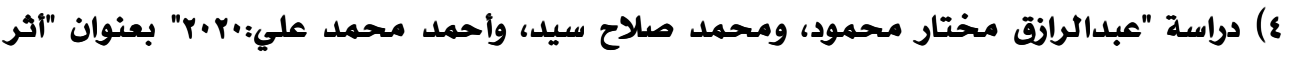

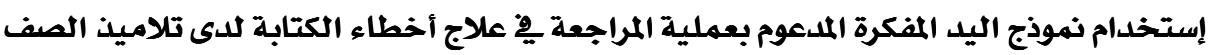

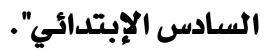

هدفت الدراسة إلى علاج أخطاء الكتابة لدى تلاميذ الصف السادس الابتدائي،

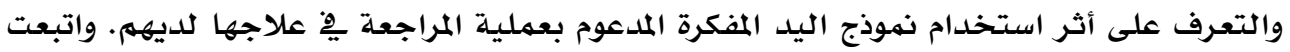

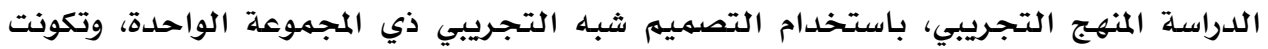

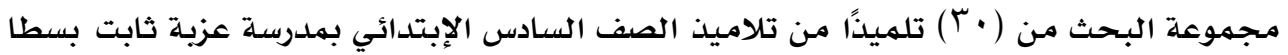

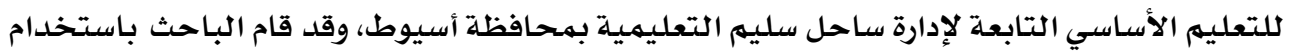

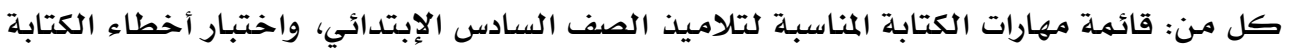

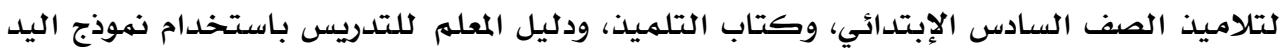

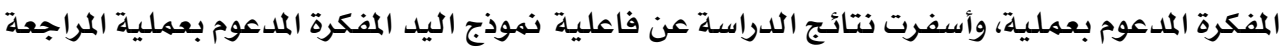


يخ علاج أخطاء الكتابة لدى تلاميذ الصف السادس الإبتدائي، ووجود أثر كبير للنموذج يخ علاج تلك الأخطاء؛ حيث بلغت قيمة حجم الأثر (ساء ( ه . . ).

ه)- دراسـة " إيمان حسن حسن زغلول :rا.r" بعنوان" أثر استخدام أنماط الرسومات التعليمية البارزة والخبرة البمرية السابقة فِ تنمية مهارة الرسم والقدرة على التخيل لدى التلاميذ المكفوفين فِ مرحلة التعليم الابتدائى".

تتمحور مشكلة هذه الدراسـة حول الصعوبات التي يواجهها الطفل الكفيف ِِّ إدراك

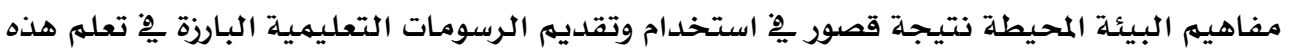
المفاهيه خلال الأنثطة الفنية لدى الكفيف. وقد هدفت الدراسة إلى التوصل إلى الأنهاط المناسبـة للرسومات التعليمية البارزة يخ تعلم وتلريب الطلاب المكفوفين على تعلم مفاهيه البيئة المحيطة، واستخدام هذه الرسومات بشكل يناسب احتياجات المكفوفين ويساعدهم يِ إكسـاب مهارات فنيـة للتعبير عن النفس وتنهية قدراتهم. من هنا حاولت هذه الدراسـة قياس أثر التعلهم بأنهاط الرسومات

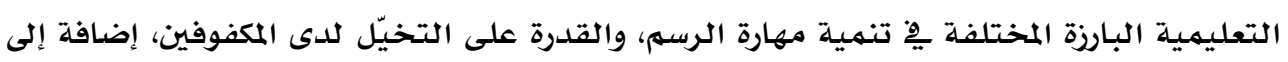
قيـاس أثر الخبرة البصريـة السابقة يف تنمية هاتين المهارتين. وقد بيّنت النتائج تساوي المجموعات التجريبية يِّ مهارة الرسهم وقدرة التخيل بادرغهم من استخدام أنهاط متتوعة للرسومات التعليميـة

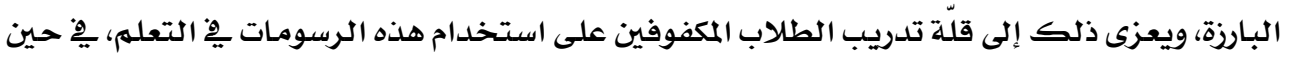

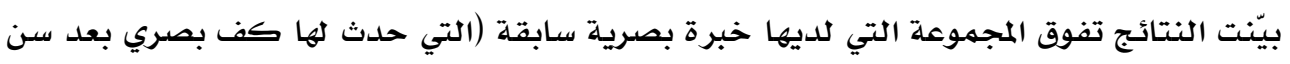

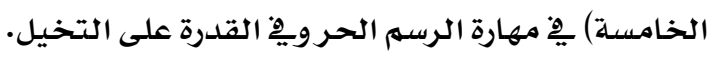

7)- دراسـة "ماهر إسماعيل صبري:19 •ץ" بعنوان "أثر الكتاب الصوتي الرقمي فى تنمىة مهارات

التعبىر الشفوي باللغة الإنجلىزىة للى الطلاب المكفوفىن بالمرحلة الثانوىة".

هدف البحث إلى قىاس "أثر الكتاب الصوتي الرقهي يِّ تنهىة مهارات التعبىر الشفوي باللغـة الإنجلىزىى لدى الطلاب المكفوفىن بالمرحلة الثانوىة"، ومن أجل ذلك تم إعداد قائمـة

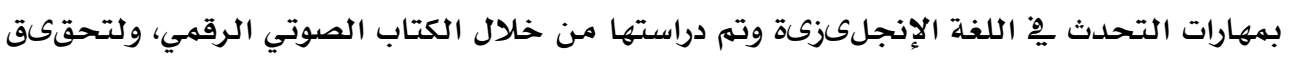

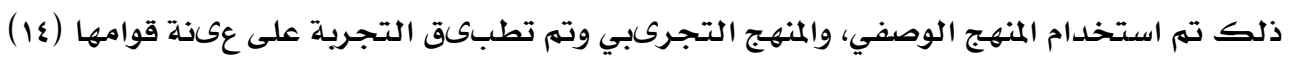
طالبًا وطالبـة من الطلاب المكفوفىن كلاشتراتك يِ البحث بالصف الأول الثانوي بمدارس النور للهكفوفىن يخ كل من مدىنة بنها بهحافظة القلىوبىة - والزقازىق بالشرقىة)، وتم

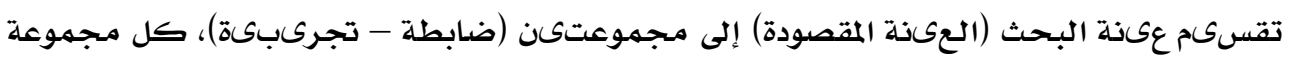
مكونة من (v) طالبًا وطالبة، وتم تطبىق أدوات البـحث قبلىًا وبعدىًا وهي اختبار يْ مهارات

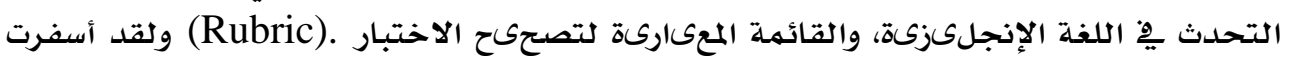
نتائج البحث عن وجود فرق ذو دلالة إحصائىة عند مستوى (1+..) بـىن متوسطىي درجات المجمهوعة الضابطة التي تستخلم الطرىقة التقلىدىة باكتتاب المدرسي والمجموعة التجرىى التبىقة التي تستخدم الكتاب الصوتي الرقهي پِ التطبىق البعدي لاختبار مهارات التحدث لصاتح المجموعة التجرىى ابكىة. 
مجلة بحوث التربية النوعية- علدد •r.r.r. - أكتوير

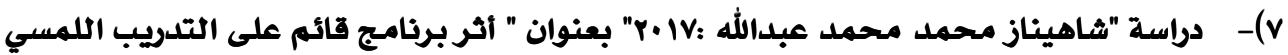
للطفل المعاق بصريًا يِ تنمية مفهوم الذات الأكاديمي".

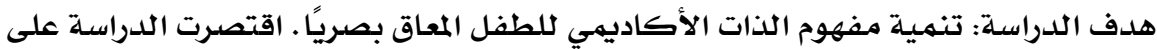

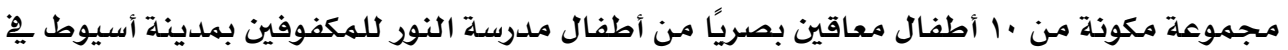

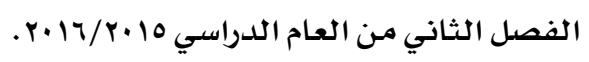

مواد الدراسـة وأدواتها: برنامـج التدريب اللمسي للطفل المانس المعاق بصريًا، مقياس مهارات

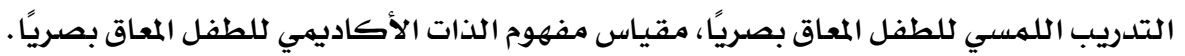
نتائج الدراسـة: - ت

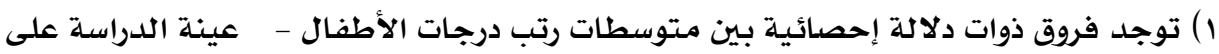

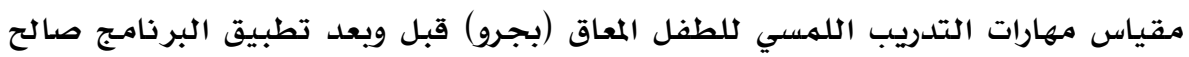
التطبيق البعدي.

r) لبرنامـج التدريب اللمسي قوة تأثير وفاعلية كبيرة يِّ تنمية مهارات التدريب اللمسي.

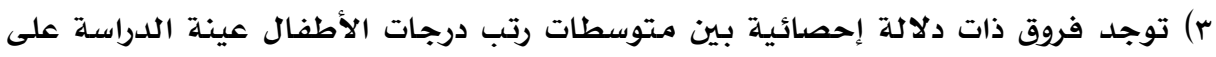

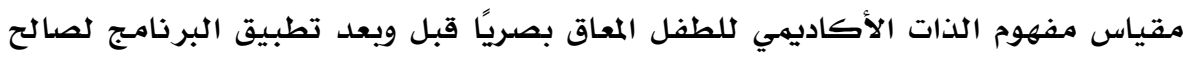

$$
\text { التطبيق البعدي. }
$$

ع) لبرنامج التدريب اللمسي قوة تأثير كبيرة وفاعلية متوسطة يِّنمية تنمية مفهوم الذات

$$
\text { الأكاديهي للطفل المعاق بصريًا. }
$$

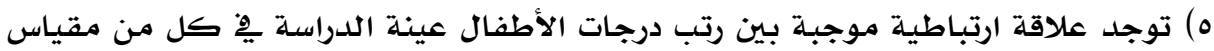
مهارات التدريب اللمسي ومقياس مفهوم الذات الأكاديمي للطفل موتل المعاق بصريًا.

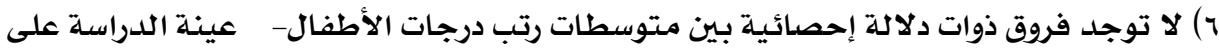

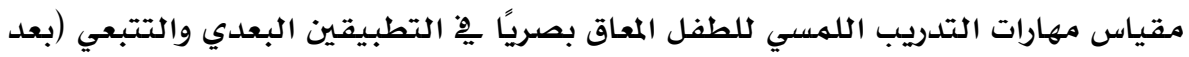

$$
\text { مـرور شهر من تطبيق البرنامج). }
$$

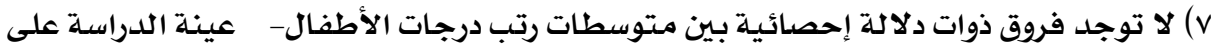

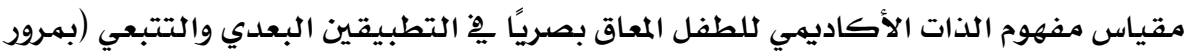

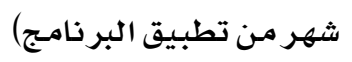

1)- دراسة "فاطمة السيد عبد العظيم أبو شوك :17 +r" بعنوان "المهارات السمعية اللازمة للتلاميذ

المكفوفين بالمرحلة الابتدائية".

$$
\text { تتمثل أهداف الدراسة بما يلي: }
$$

1) إعداد قائمة بالمهارات السمعية الدلازمة للتاميذ المكفوفين بالمرحلة الابتدائية. 
r) تعرف مصادر اشتقاق قائمسة المهارات السمعية الكلازمـة للتلاميذ المكفوفين بالمرحلة الابتدائية.

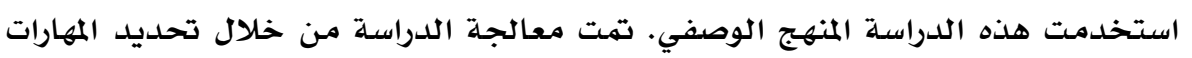

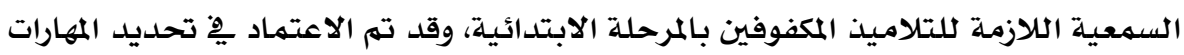

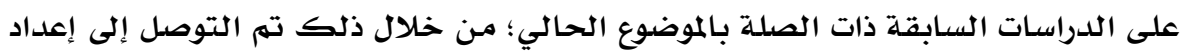

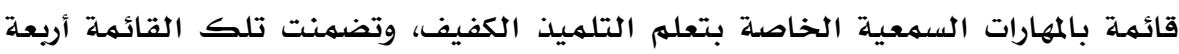

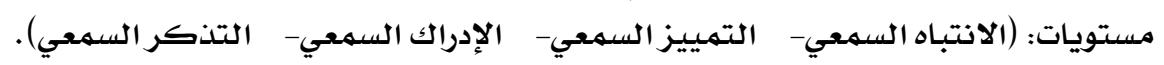

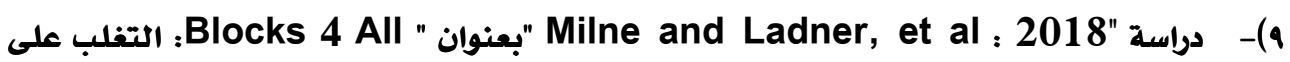

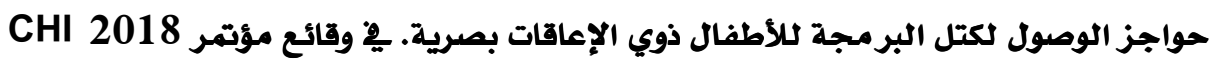

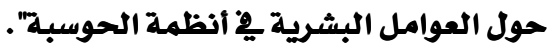

قام الباحثون ِِّ هذه الدراسة بفحص تسعة برامـج لتعليم البرمجة للمكفوفين بطرق

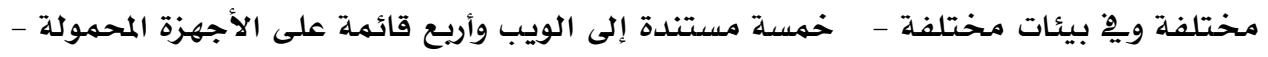

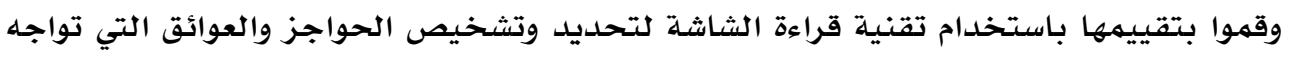

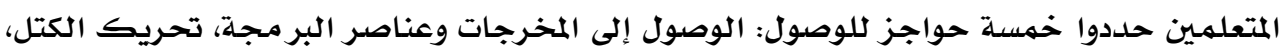

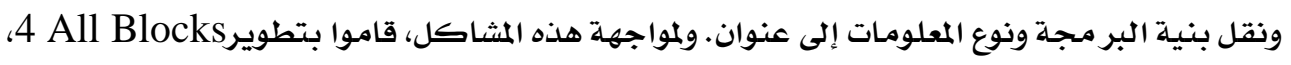

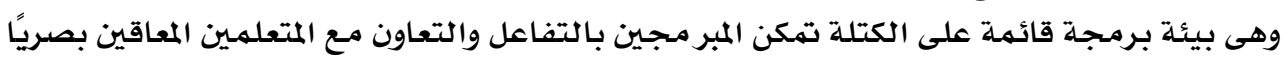

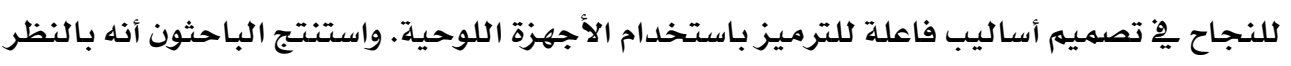

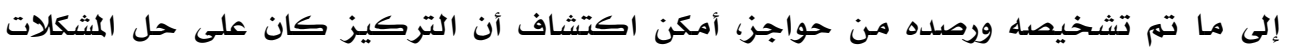

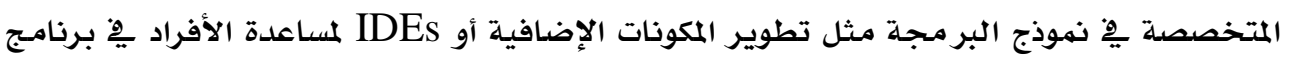

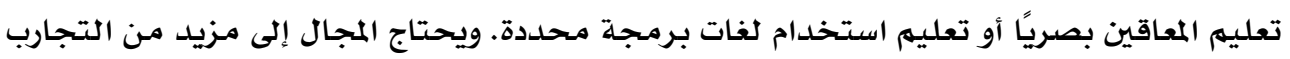

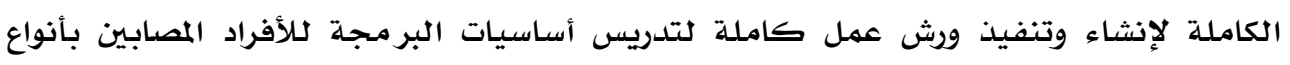

$$
\text { ومستويات الإعاقات البصرية. }
$$

المحور الثاني: دراسات تناولت تتنمية المهارات الفني: والبهن: 1) دراسة "Annie Penda : 2018 " "بعنوان " طريقة تدريس التربية الفنية للمتعلمين ذوي

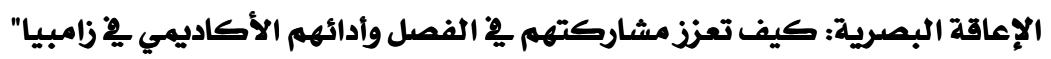

استهدفت الدراسلة تنفيذ استراتيجيات تدريس تعتمد على استخدام عناصر التعلم الأريعة

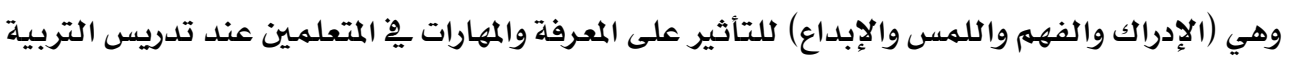

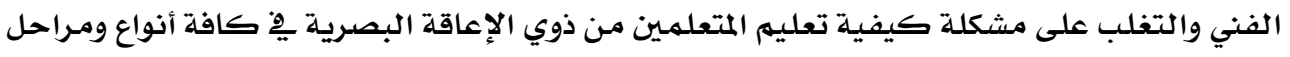

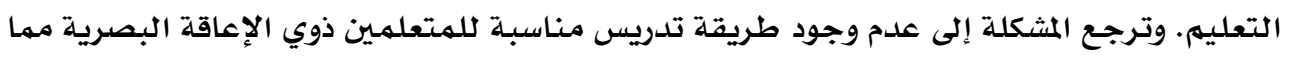

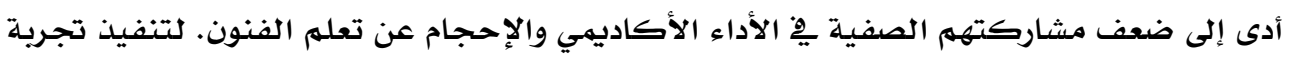

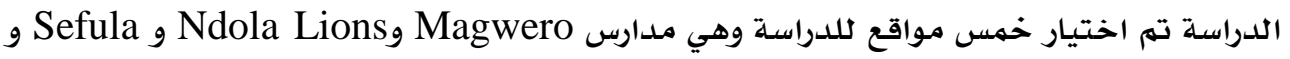

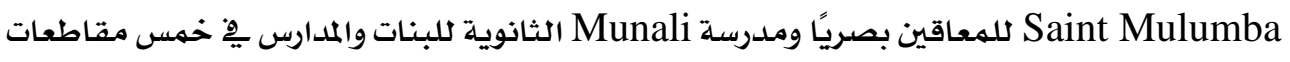
مِّ زامبيا تضم الطلاب الذان يعانون من إعاقات بصرية. 
مجلة بحوث التربية النوعية - علدد •r.r. - م أكتوير

استخدمت الباحثة الأدوات الرئيسية الآتية: الاستبيانات والمناقشات الجماعية المركزة وقوائم التدقيق وبطاقات الملاحظة والمراقبة.

وفرت البيانات الشاملة والمتنوعة التي تم جمعها من استخدام هذه الأدوات ضمانات لصحة

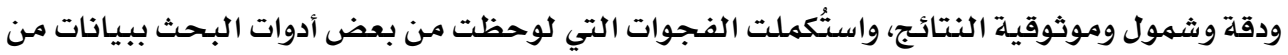

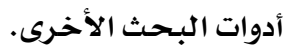

إستنتجت الدراسة أن طريقة تدريس التربية الفنية باستخدام عناصر التعلهم الأربعة وهي

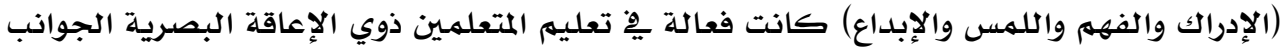

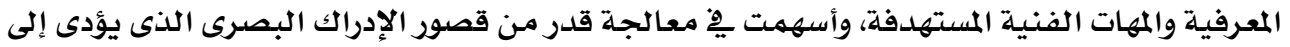

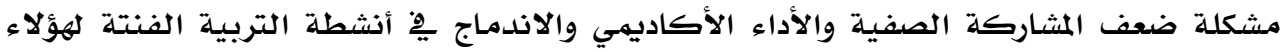

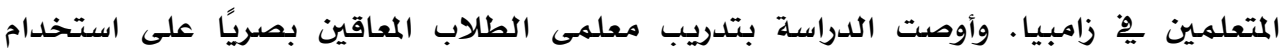
استراتجيات تدريس مماثلة لمواجة مشكلات تدريس التربية الفنية للطلاب المعاقين بصريًا. r) دراسة "Kate Phoenix : 2018 منوان " قيمة تعليم الفنون البصرية للتلاميذ الذين يعانون من إعاقة بصرية مشروع BEd 4 مقدم كمتطلب للوفاء الجزئي بمتطلبات درجة بكالوريوس التربية فِ الفن والتصميم" بصريم مشرع

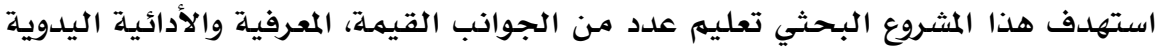

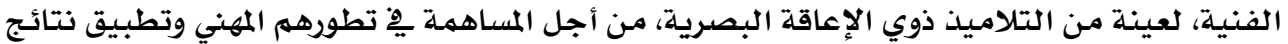

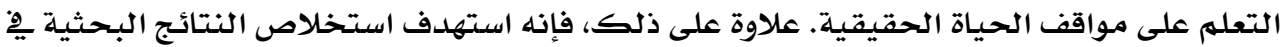

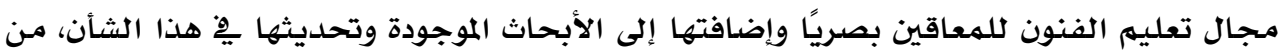

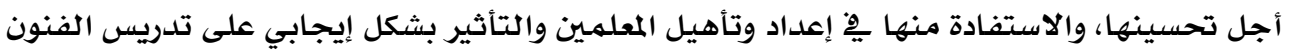

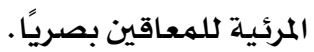

قامت الباحثة بمراجعة الأدبيات ذات الصلة بالموضوع. واستعانة بأدوات ومناهج البحث

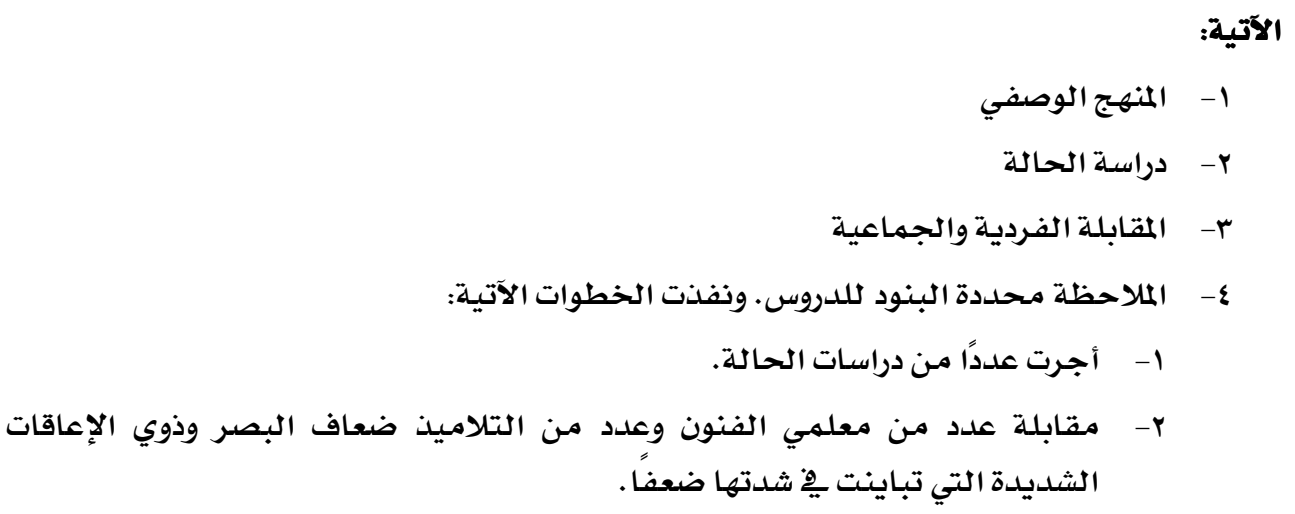


ب- لاحظت دروسًا لعينة من التلاميذ المبصرين والمعاقين بصريًا . بعد ذلك أجريت مقابلة

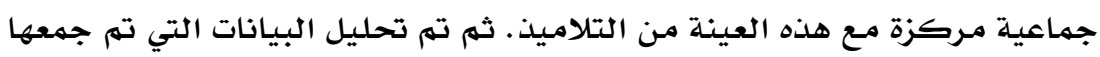

بدقة وتفسيرها.

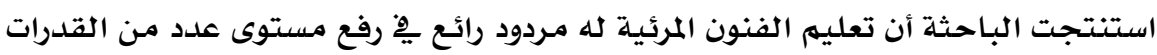

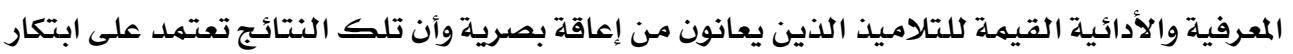

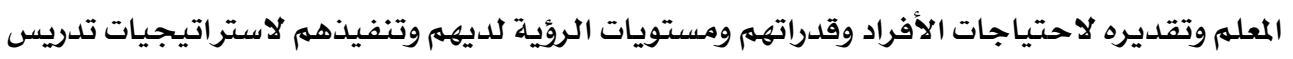

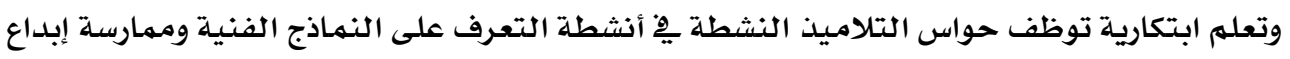
أعمال على غرارها.

حددت الدراسـة عددا من الفوائد التعليميلة الأوسع التي يمكن أن يوفرها تعليم الفنون

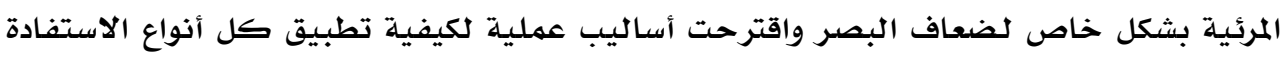

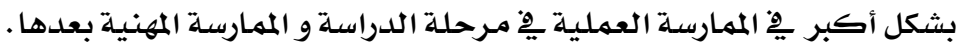

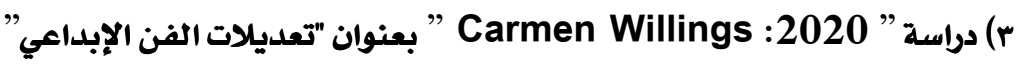
تشير هذه الدراسة الوصفية التي اعتمدت الباحثة فيها على أنواع من بطاقات

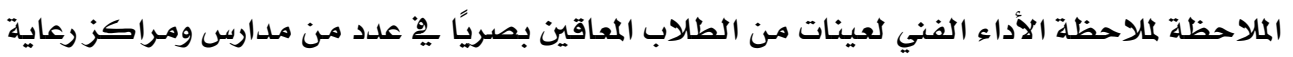

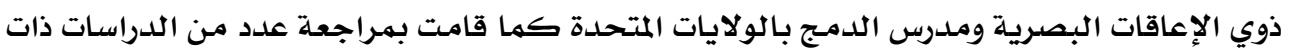

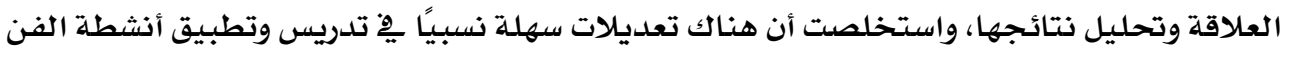

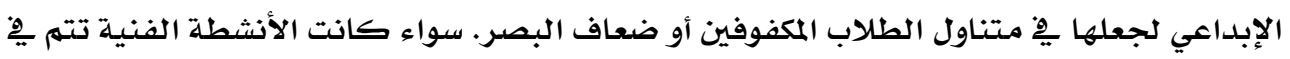

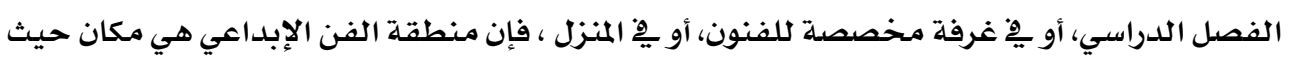

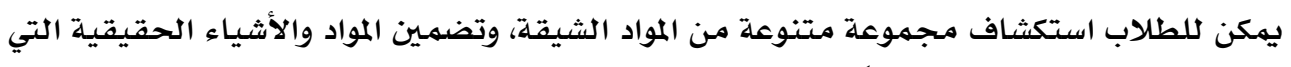

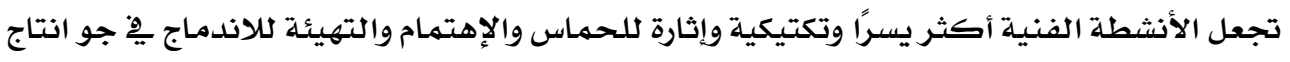
الفنون.

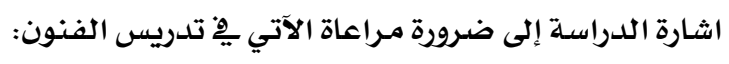

ا- إن توظيف المواد والأشياء الحقيقية يوفر كلأفراد وسيلة للتعبير عن الذات والأصالة ويمكن مئن

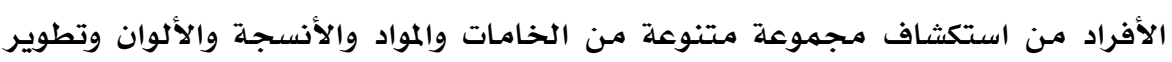

$$
\text { المهارات الحركية الدقيقة. }
$$

ץ- إن إضافة الروائح والقوام واستخدام مجموعة متنوعة من المواد ذات الأبعاد المتعددة ييسر

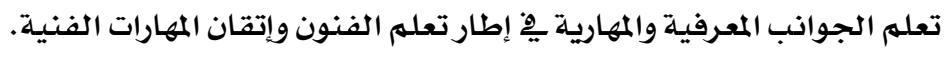
r- فاعلية تقديم توجيهات شفهية حول جميع أجزاء وخطوات النشاط مـع الاستفادة من كافة الحواس النشطة. 
مجلة بحوث التربية النوعية- علدد •r.r.r. - أكتوير

ع- عندما يسمـع الطالب المعاق أن الطلاب الآخرين يتلقون أوصافا موجهة لتيسير استكمال

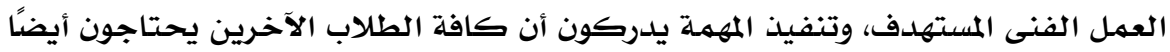

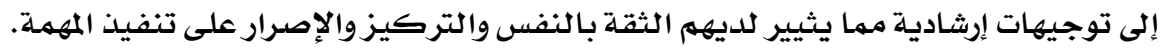
ه- يْ حالة عدم وجود خبرة فنية سابقة، قد لا يعرف الطالب من أين يبدأ بمشروع إبداعي

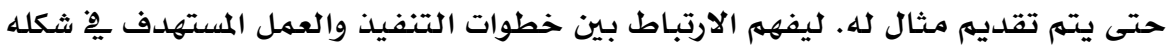
النهائي. 1- توفير أشياء حقيقية تمثلها الحرفة كنموذج بِ شكلها النهائى يساعد الطالب يِّ تخيل

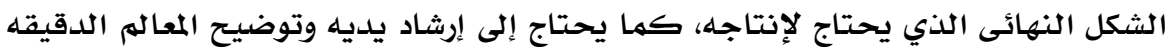
للمنتج المستهدف. V- يفضل إتاحة ألوان متبـاينة واستخلدم مواد ذات تباين واضـح بشكل عام. ^- الطلاب ذوو الرؤية الدنيا أو معدومي الرؤية يحتاجون إلى فهم تمثيل الصورة أو المشروع

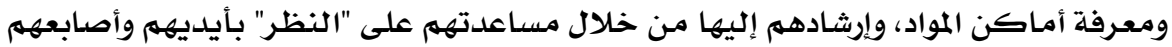
واصطحابهم وتوجيه تحركاتهم شفهيًا. 9- إنشاء مخطط أو حلدود تكتيكية للمنطقة التي يحتاجون إلى تلوين أبعادها، أو استخدام

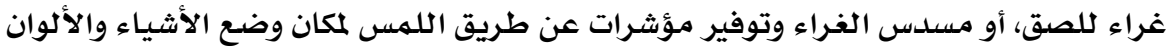

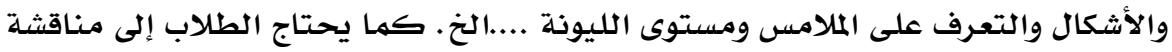

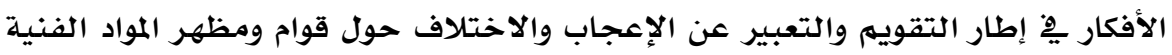
المتاحة والمنتجات النهائية.

ع ) دراسة "Al-Dababneh, et al: 2015 " "بعنوان" أثر برنامج تدريبي ـِ الإبداع بِ تنمية القدرات الإبداعية لدى الأطفال ذوي الإعاقة البصرية.

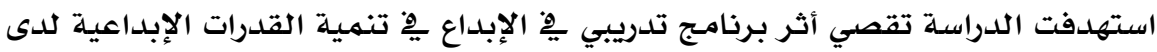

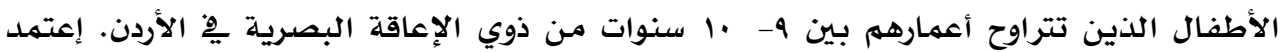

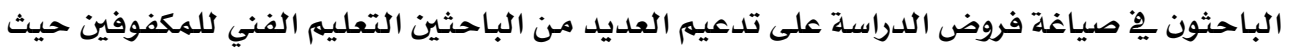

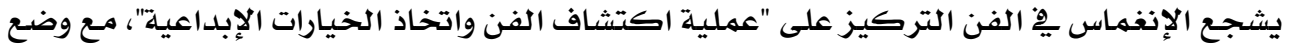

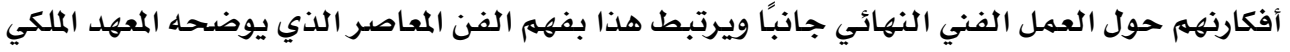

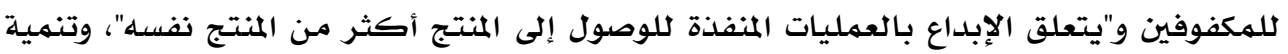

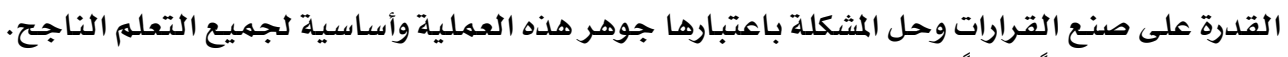

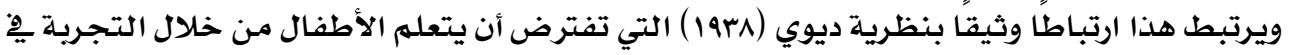

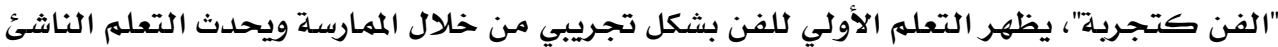

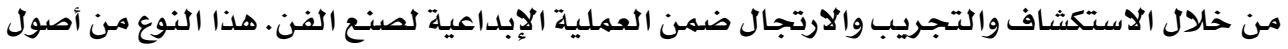

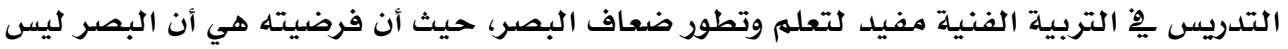

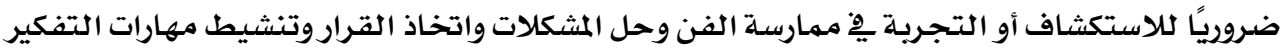


المتشعب والمخاطرة والتعلهم من الفشل وكلها جزء من عملية التنفيذ ، وهو شيء يستطيع ضعاف

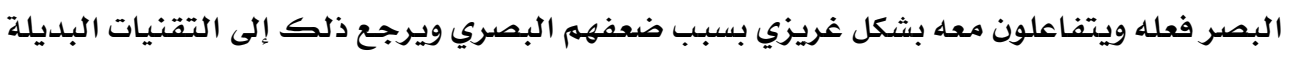

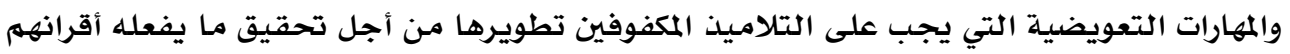

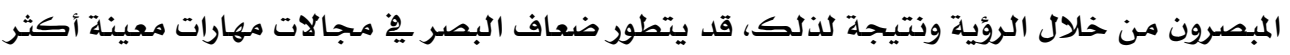

$$
\text { من نظرائهم المبصرين. }
$$

تكونت عينة الدراسة من اء طالبًا من الصفين الرابع والخامس، تم اختيارهم عشوائيًا

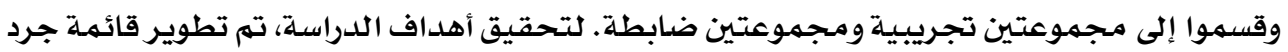

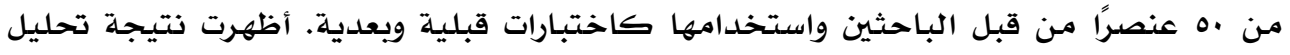

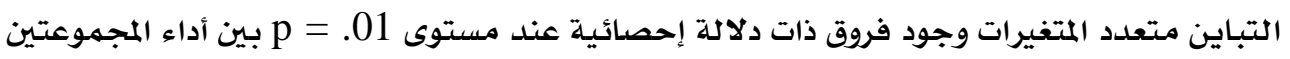

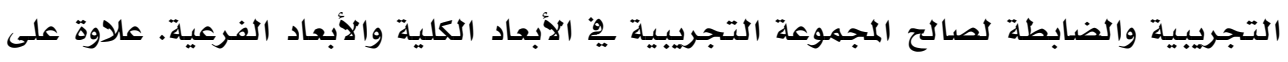

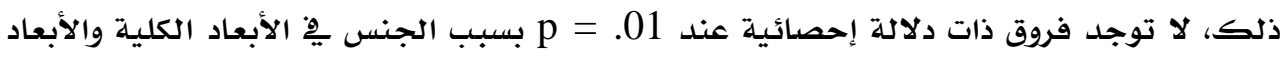

$$
\text { واستنتج الباحثون الآتى: }
$$

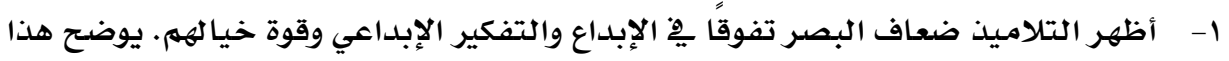

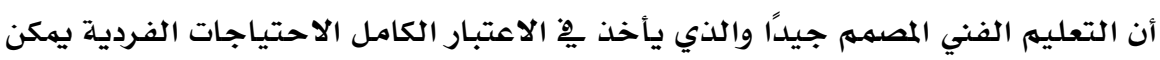

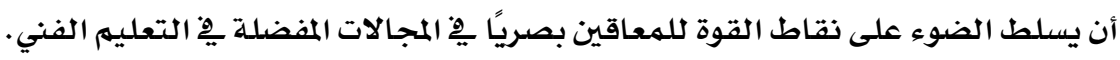

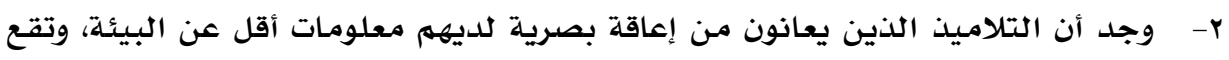

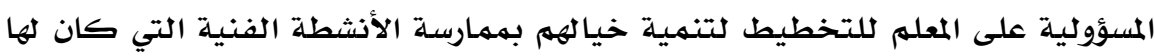

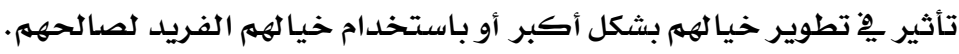

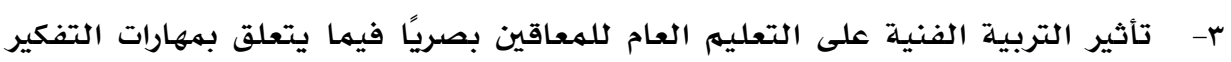

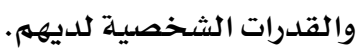

ع- إيجابية الطلاب يِّ المواقف تجاه التعلهم وارتفاع مستوى المشاركة. 5- التركيز على الاهتمام بتطوير التعبير، والملاحظة، والتفكير، والتقييم، والمشاركة، والمثابرة والقدرة. 1- توقع نقل هذه المهارات التي تم اكتسابها ِِّ التعليم الفني إلى مجالات أخرى من التعلم

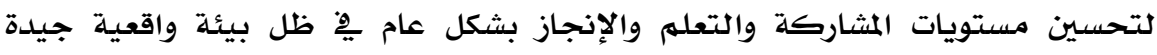

$$
\text { التخطيط والموارد. }
$$

\section{التعهيق العام على الدراسات السابقة:}

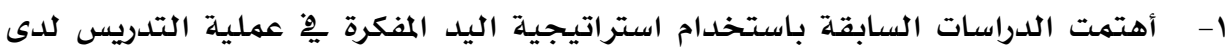

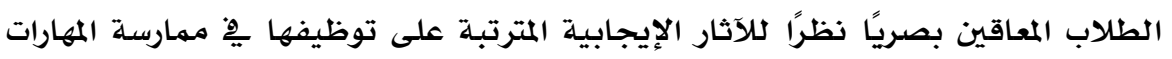


مجلة بحوث التربية النوعية - علدد •r.r. - م أكتوير

ب- هدفت الدراسات السابقة إلى تنمية المهارات الفنية المختلفة يٌْ النواحي الفنية المتعددة وغيرها.

ץ- أثبتت الدراسات السابقة فعالية استخدام استراتيجية اليد المفكرة والاستراتيجيات المماثلة

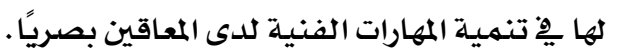
ع- تنوعت المواد الدراسية التي أجريت عليها الدراسـة السابقة فمنها (العلوم- الفيزياء...). 0- استخدمت معظم الدراسات المجموعة التجريبية والمجموعة الضابطة.

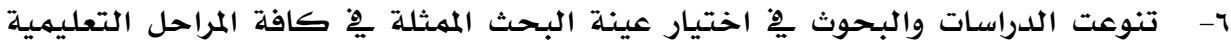
(الإبتدائية والثانوية).

\section{استفادة البحث العالي هن الدراسات السابقة:}

تهثلت أوجها الاستفادة من الدراسات السابقة فيما يلي:

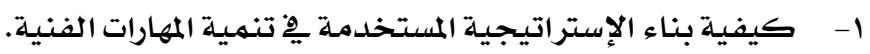

r- إعداد محتوى منهج التربية الفنية لطلاب الصف الأول الثانوي المعاقين بصريًا.

r- ب اختبار العينة والضبط التجريبي لها وتقسيمها إلى مجموعتين (ضابطة وتجريبية). ع- الاسترشاد ببعض الدراسات ِِّ إعداد أدوات الدراسة (الاختبار التحصيلي، وبطاقة

ملاحظة).

ه- بناء الإطار النظري للبحث الحالي والتعرف على الأساليب والطرق البحثية وتحديد

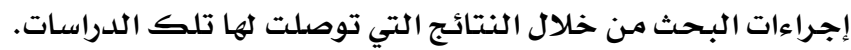
ז- الاستعانة بنتائج الدراسات السابقة يِّياغة الفروض الحالية للبحث.

$$
\begin{aligned}
& \text { - - اختيار الأسـاليب الإحصائية المناسبة. } \\
& \text { 1- عرض وترتيب محاور الإطار النظري للبحث. } \\
& \text { 9- تفسير ومناقشة نتائج البحث الحالي. }
\end{aligned}
$$

فروض البحث

1- توجد فروق دالة إحصائيًا عند مستوي دلالة (\ه...) بين متوسطات رتب فروق درجات

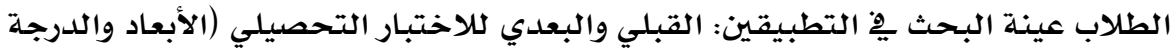

$$
\text { الكلية) لصالح التطبيق البعدي. }
$$

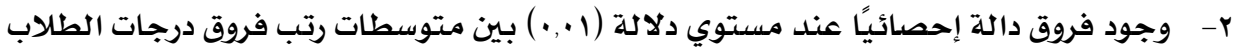

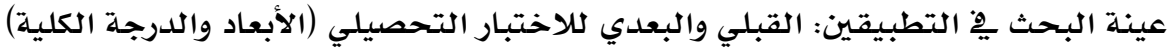

$$
\text { لصالح التطبيق البعدي. }
$$




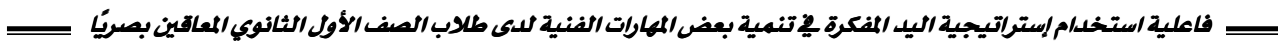
ץ- توجد فروق دالة إحصائيًا عند مستوي دلالة (\ه...) بين متوسطات رتب فروق درجات

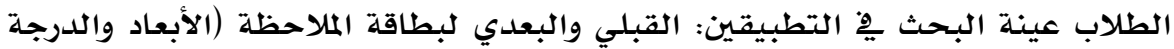
الكلية) لصالح التطبيق البعدي.

\section{إبراsات البمث}

ا- الاطلاع على الأدبيات والدراسات السابقة المتعلقة بمتغيرات البحث والاستفادة منها ـِِ

$$
\begin{aligned}
& \text { مجال البحث الحالي. } \\
& \text { Y- إعداد دليل المعله }
\end{aligned}
$$

تم إعداد دليل المعلم لتدريس منهج التربية الفنية المعدل للطلاب الصف الأول الثانوي المعاقين بصريًا وفق ما يلي:

\section{تخطيط دليل المعلم وذلك هن خلال}

• تحليل خصائص المتعلمين ( ـ ) طلاب منهم (ج) ذكورو (r) إناث.

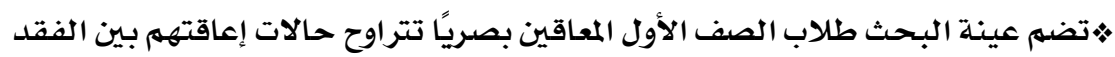

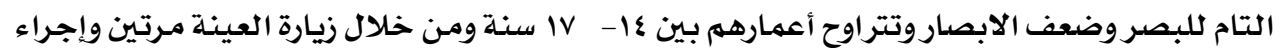

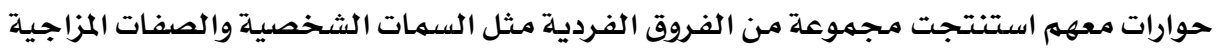
ومستوي تأثر كل منهم بظروف الإعاقةت موتئ.

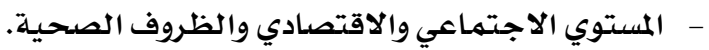

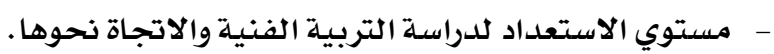

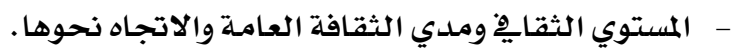

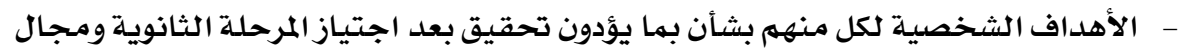

$$
\text { • تحديد احتياجات الطلاب من مقرر التربيل العمل به. . الفية الفنية. }
$$

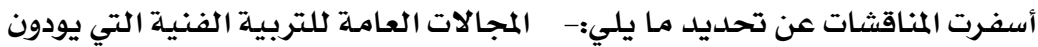

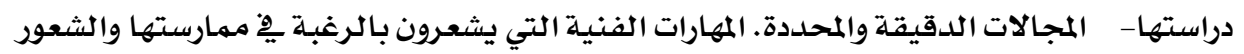

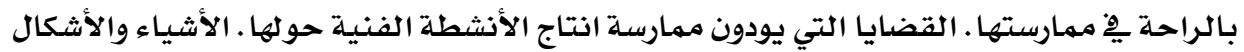

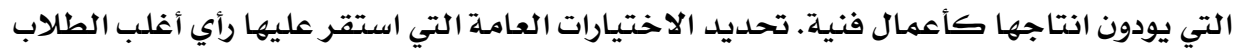

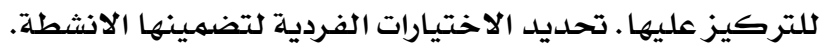

\section{بناء علي المرحلة السابقة تم:}

• تحليل المحتوي (محتوى منهج التربية الفنية للصف الأول الثانوي وتعديله ليلائم احتياجات

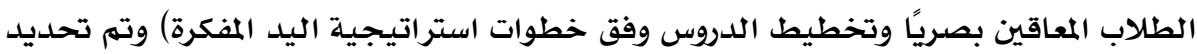


مجلة بحوث التربية النوعية - علدد •r - أكتوبر م.r.

المفاهيه والحقائق والمهارات المراد تعليهها كخبرات يِّ أنشطة تدريس / تعلم المنهج من قبل عينة البحثث. • تحديد الاهداف التعليميـة وذلك من خلال: • استخلاص الخبر ات التعليهيلة المراد تعلهها فٍِ ضوء الأهداف العامـة للهنهج. • تحديد الخبر ات والمعارف المستهدفه (حقائق- مفاهيه - تعميهات - مبادئ ..). • تحديد الأهداف (معرفية - مهارية -وجدانية ). (بمستوياتها الست وفق تصنيف بلوم) . • صياغة الأهداف ِِّ صورة إجرائي.

نتائج التمايل:

ِِِ ضوء مـا أسفر عنـة تحليل الأهداف ثم تحديد المحتوي وخطة التنفيذ كما يلى:

(1) جدول)

الخطة الزمنية لتوزيع وتنفيذ محتوى مادة التربية الفنية للصف الأول الثانوي المعدل من التعليم العام إلى

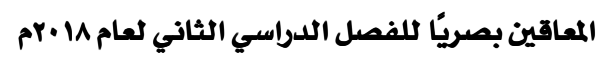

\begin{tabular}{|c|c|c|c|}
\hline الموضومات & التاريخ & الأسبوع & |lins \\
\hline ل ملماذا التذوق الفني؟ & $r+1 \Lambda|r| \varepsilon$ & الأول & \multirow{4}{*}{ 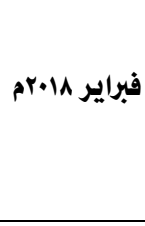 } \\
\hline 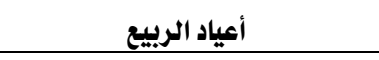 & $r+|\Lambda| r \mid 11$ & 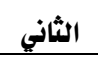 & \\
\hline \multirow[t]{2}{*}{ الطبيعة الصامتة } & $r+|\Lambda| r \mid \Lambda \Lambda$ & 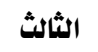 & \\
\hline & $r \cdot I N|r| r o$ & 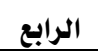 & \\
\hline \multirow[t]{2}{*}{ قاع البحر } & $r+1 \Lambda|r| \xi$ & الأول & \multirow{4}{*}{ 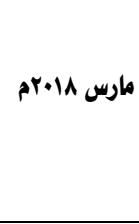 } \\
\hline & $r+|\Lambda| r \mid 11$ & 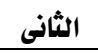 & \\
\hline \multirow[t]{2}{*}{ 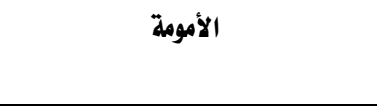 } & $r+|\Lambda| r|| \Lambda$ & 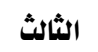 & \\
\hline & $r+|\Lambda| r \mid r o$ & 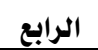 & \\
\hline الفن الشعبي & $r+|\Lambda| \xi \mid r$ & الأول & \multirow{4}{*}{ 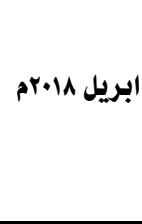 } \\
\hline تشكيل مجسم للوجه أقرب إلى الشكل & $r+|\Lambda| \xi \mid \Lambda$ & 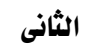 & \\
\hline الكروي أو البيضاوي & $r+|\Lambda| \xi \mid 10$ & الثالث & \\
\hline رواد الفز التشكيلي & $r+1 \Lambda|\xi| r r$ & الرابع & \\
\hline
\end{tabular}

وروعي أن تلائم ظرف الطلاب عينـة البحث وتم اختيـارها واختيار المواد والأدوات بهشاركة

$$
\text { الطلاب ومدرس الفصل . }
$$

• إعداد أماكن تتواجدالطلاب بحيث تناسب ظروف كل طالب، حيث سيكون ِِوضع محدد

$$
\text { ومكان ثابت علي مدى فترة إجـراء التحبريسة. }
$$




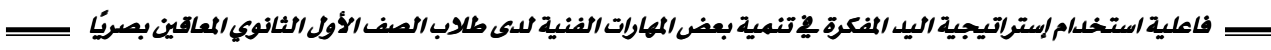

• إعداد المواد والأدوات وتحديد أماكنها لتكون معروفه لدي كل طالب وِِّناول يده.

• مناقشة وتقديه خطوات استراتيجية اليد المفكرة وتعريف الطلاب بخطوات تنفيذها ومناقشة

مبررات كل خطوة وبيان فوائدها ومـيزاتها علي غيرها .

• تنفيذ الدروس وفق كتاب المعلم الذي يتضمنـه عرض الدروس وفق خطوات استراتيجية اليد

المفكرة.

r- إعداد الاختبـار التحصيلي وضبطه.

ع- إعداد الاختبار المهاري وضبطه.

0- إعداد بطاقة الملاحظة وعرضها علي مجحموعة المحكمـين.

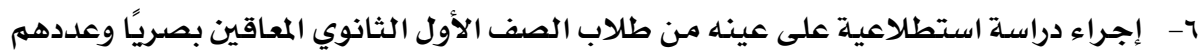

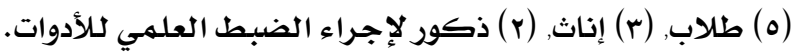

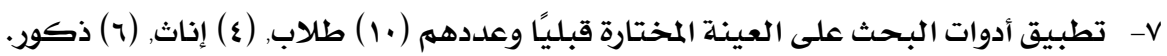
^- - تدريب طلاب عينة البحث على المهارات الفنيـة بتدريس المقرروتطبيق استراتيجية اليد

المفكرة.

و- تطبيق أدوات الدراسـة على العينـة المختارة بعديًا وعددهم ( • () طلاب, (ع ) إناث, (ج) ذكور. 10- رصد البيانات الناتجة عن التطبيق القبلي والبعدي. 11- المعالجة الإحصائية للبيانات بالأساليب الإحصائية المناسبـة.

نتائج الدراسة وهناقشتها وتفسيرها: أولاً: تحليل النتائج وتفسيرها:

() اختبار صحة الفرض الأول من فروض البحث:

ينص الفرض الأول من فروض البحث علي "تواجد فروق دالة إحصائيًا عند مستوي دلالة

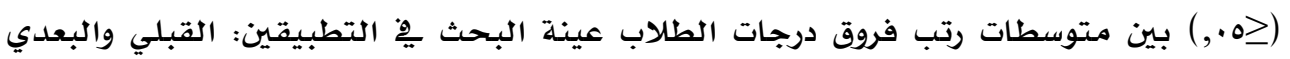

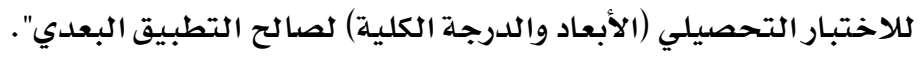

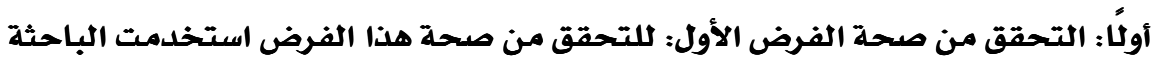

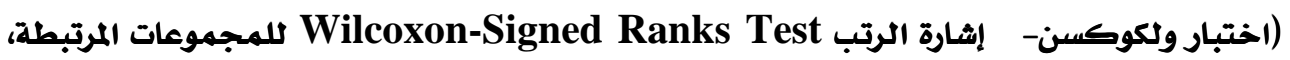
ويوضع جدول (9) هذه النتائج: 
مجلة بحوث التربية النوعية - علدد •r.r.r. - أكتوبر

جدول (2)

المقارنة بين متوسطات رتب فروق درجات الطلاب عينة البحث يِ التطبيقين: القبلي والبعدي للاختبار

التحصيلي (الأبعاد والدرجة الكلية)

\begin{tabular}{|c|c|c|c|c|c|c|}
\hline مستوى & $\begin{array}{l}\text { قيمة } \\
\text { Z) } \\
\end{array}$ & مجموع الرتب & متوسط & j & الرتب & الأبعاد \\
\hline \multirow{2}{*}{,+1} & \multirow{2}{*}{$r, \wedge \leqslant \cdot-$} & . & • & . & السالبة & \multirow{2}{*}{ تذكر } \\
\hline & & $\Delta 0$ & $0,0$. & 1. & الموجبة & \\
\hline \multirow{2}{*}{, } & \multirow{2}{*}{$r, \Delta r{ }_{-}$} & . & . & . & السالبة & \multirow{2}{*}{ فهم } \\
\hline & & $\Delta 0$ & $0,0$. & 1. & الموجبة & \\
\hline \multirow{2}{*}{,+1} & \multirow{2}{*}{$r, \wedge \vee q_{-}$} & • & • & • & السالبة & \multirow{2}{*}{ تطبيق } \\
\hline & & $\Delta 0$ & $0,0$. & 1. & الموجبة & \\
\hline \multirow{2}{*}{, } & \multirow{2}{*}{$r, A T I-$} & . & . & . & السالبة & \multirow{2}{*}{ عليا } \\
\hline & & $\Delta 0$ & $0,0$. & 1. & الموجبة & \\
\hline \multirow{2}{*}{,+1} & \multirow{2}{*}{ r,AYI- } & . & . & . & السالبة & \multirow{2}{*}{ الكل } \\
\hline & & $\Delta 0$ & $0,0$. & 1. & الموجبة & \\
\hline
\end{tabular}

يتضح من جدول (r) ما يلي:

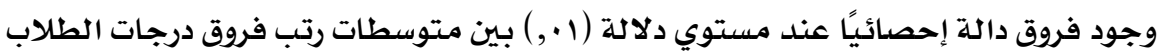

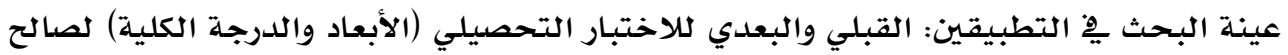

التطبيق البعدي.

وتدل هذه النتائج علي تحقق الفرض الأول من فروض البحث، ويمكن تفسير النتائج على

النحو التالي:

• ارتفاع مستوى طلاب مجموعة البحث التجريبي يِّ التطبيق البعدي للاختبار التحصيلي

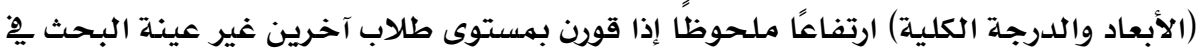
التطبيق البعدي للاختبار التحصيلي (الأبعاد والدرجة الدادئ الكلية).

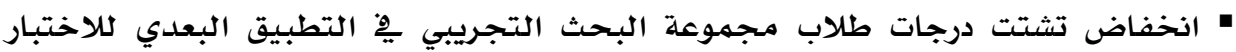

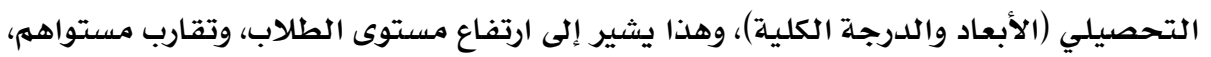

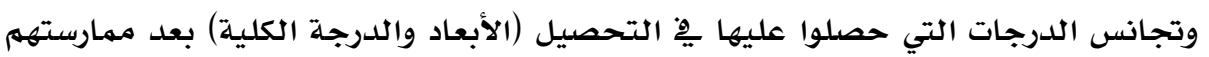

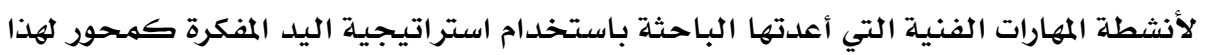
البـحث. 
وتتفق نتائج الفرض الأول من فروض البحث مـع نتائج دراسات: (هالة لطفي وآخرون،

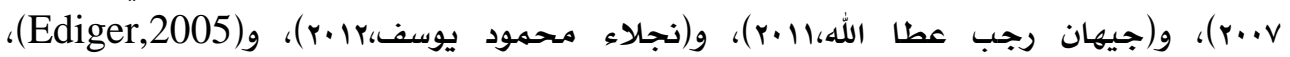

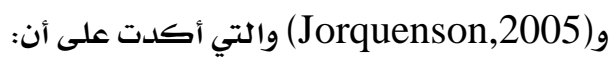

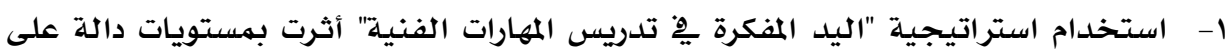

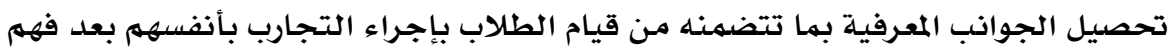

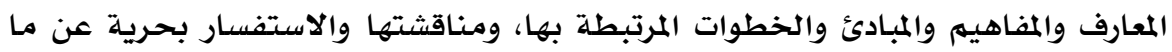

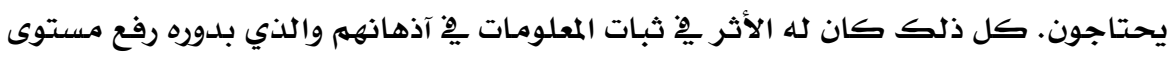

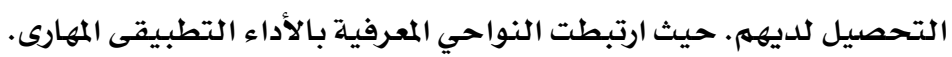

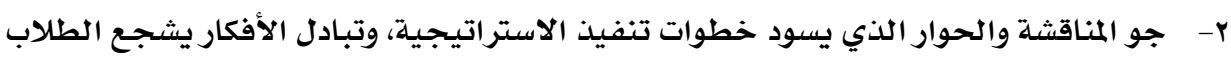

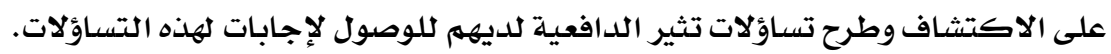

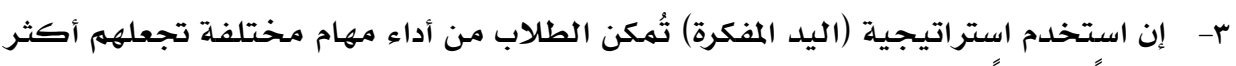

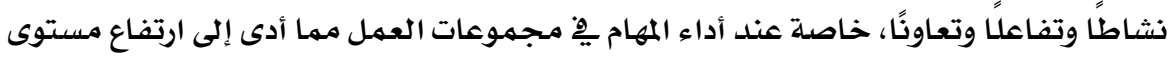
التحصيل. نشاملاوتفاعل ثانيًا: حجم التأثير: تم حساب قيمة (ت)، ومريع إيتا، وحجم التأثير، وجدول (r) يوضح ذلك:

جدول (3) (30)

حجم تأثير استخدام استراتيجية اليد المفكرة فِ تنمية تحصيل الجوانب المعرفية للمهارات الفنية لدى الطلاب المعاقين بصريًا

\begin{tabular}{|c|c|c|c|}
\hline حجم التأثير & مربع إيتا & قيمة (ت) & الأبعاد \\
\hline مرتفع &, 91 & $r r, \wedge T$ & تذكر \\
\hline مرتفع & ,qr & $M, r \cdot$ & فهم \\
\hline مرتفع & , 9. & $9, \cdot \cdot$ & تطبيق \\
\hline مرتفع & ,91 & $r, \cdot \cdot$ & عليا \\
\hline مرتفع & ,99 & AN,Or & الكل \\
\hline
\end{tabular}

يتضح من جدول (r) أن مربع إيتا لكل بعد من أبعاد الجوانب المعرفية للمهارات الفنية علي

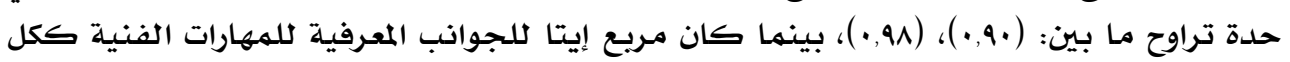

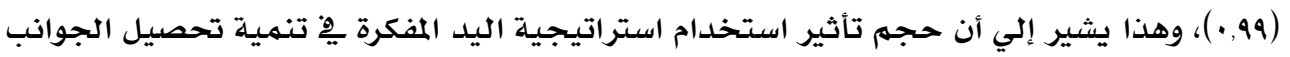

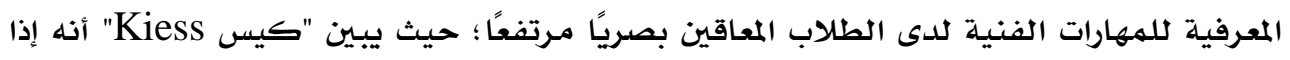

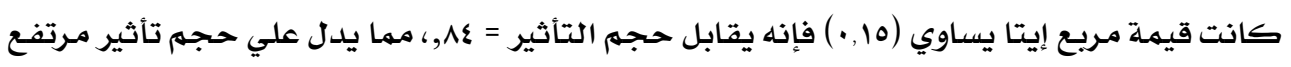

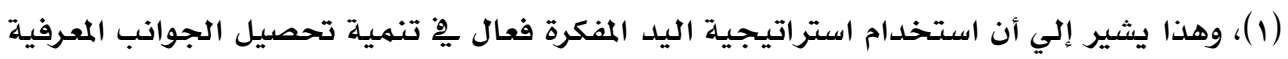

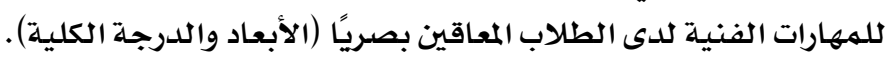


مجلة بحوث التربية النوعية- علدد •r.r.r. - أكتوير

وبذلك تكون الباحثة قد أجابت عن السؤال الأول من أسئلة البحث والذي ينص علي: "ما

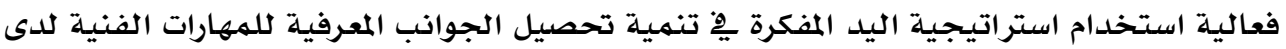

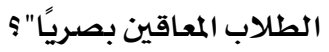

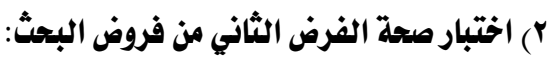

ينص الفرض الثاني من فروض البحث علي: "توجد فروق دالة إحصائياً عند مستوي دلالة

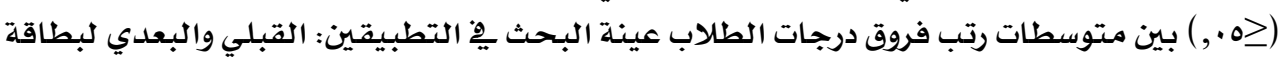
الماحلاحظة (الأبعاد والدرجة الكلية) لصالح التطبيق البعات البعدي". أولًا : التحقق من صحة الفرض الته الثاني

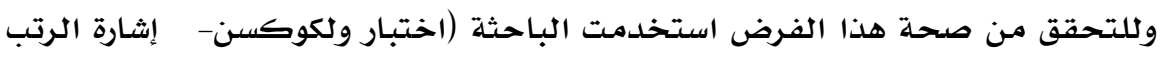
Wilcoxon-Signed Ranks Test جدول (4)

المقارنة بين متوسطات رتب فروق درجات الطلاب عينة البحث يُ التطبيقين: القبلي والبعدي لبطاقة الملاحظة (الأبعاد والدرجة الكلية البحث)

\begin{tabular}{|c|c|c|c|c|c|c|}
\hline مستوى & $\begin{array}{l}\text { قيمة } \\
Z \text { (Z) } \\
\end{array}$ & مجموع & متوسط & ن & الرتب & الأبعاد \\
\hline \multirow{2}{*}{$\cdot, \cdot 1$} & \multirow{2}{*}{$r, \wedge \leqslant r}$. & - & . & . & السالبة & \multirow{2}{*}{ ip } \\
\hline & & $\Delta 0$ & $0,0$. & 1. & الموجبة & \\
\hline \multirow{2}{*}{$\cdot,+1$} & \multirow{2}{*}{$r, \wedge \mid \wedge}$. & . & . & . & السالبة & \multirow{2}{*}{$r_{p}$} \\
\hline & & 00 & $0,0$. & 1. & الموجبة & \\
\hline \multirow{2}{*}{$\cdot, \cdot 1$} & \multirow{2}{*}{$r, \wedge l \varepsilon$} & . & . & . & السالبة & \multirow{2}{*}{ الكل } \\
\hline & & $\Delta 0$ & $0,0$. & 1. & الموجبة & \\
\hline
\end{tabular}

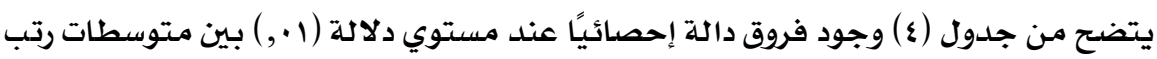

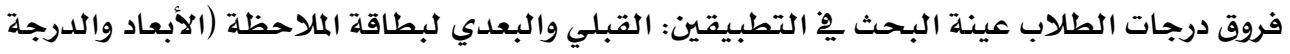
الكلية) لصالح التطبيق البعدي.

وتدل هذه النتائج علي تحقق الفرض الثاني من فروض البحث، ويهكن تفسير النتائج على النحو التالي:

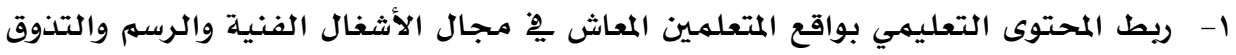

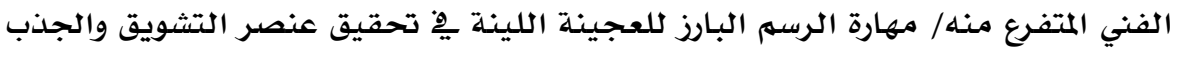

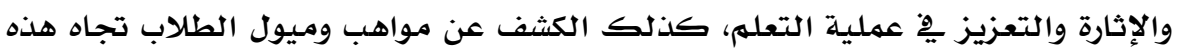

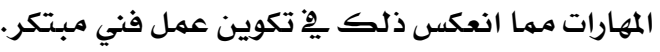


r- إعداد مستلزمات مجال تنفيذ مهارة عمل أنية خزفية بطريقة الضغط مِّ القالب ومهارة

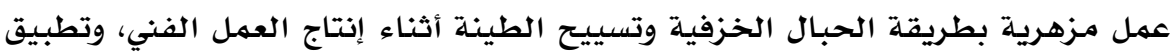

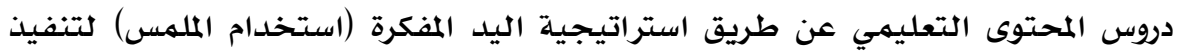

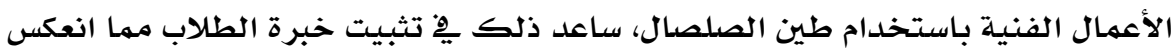

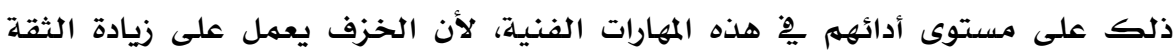

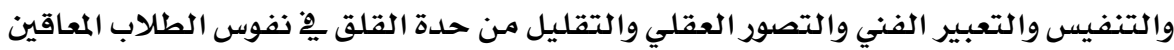

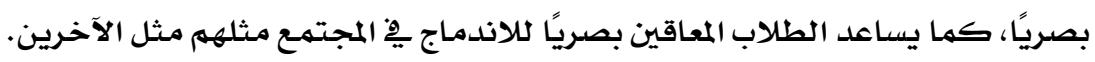

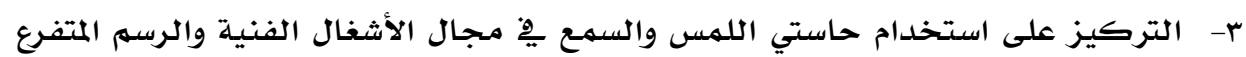

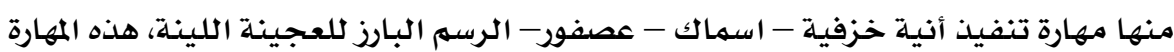

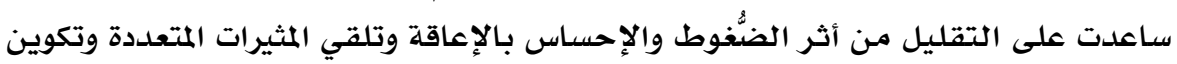

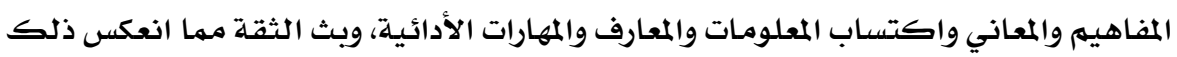

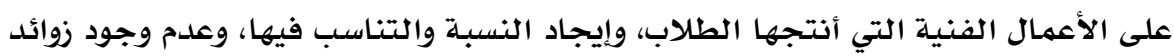

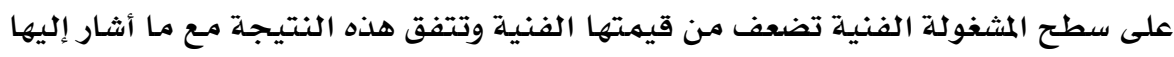

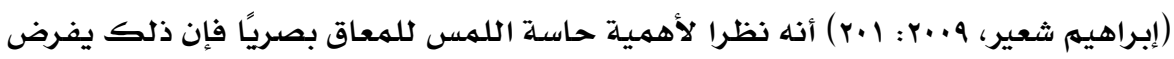

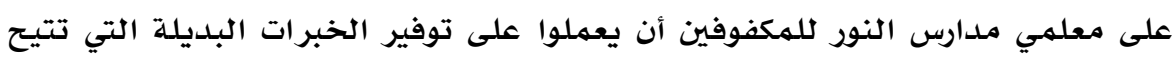

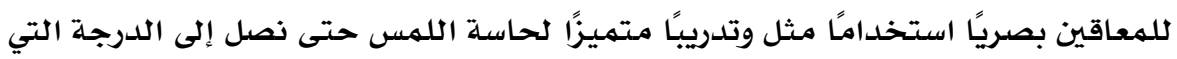

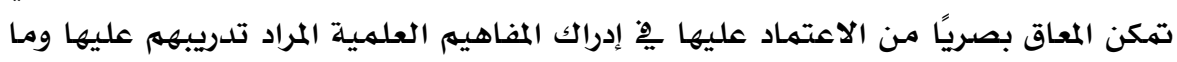
ترتبط بها من مهارات.

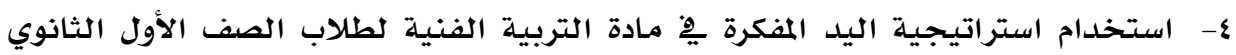

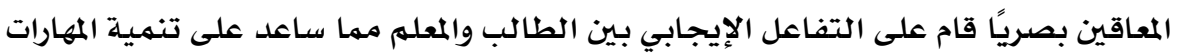

المستهدفة.

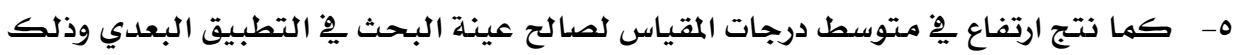

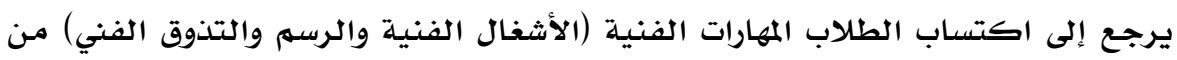
خلال تقدير الناتج النهائي.

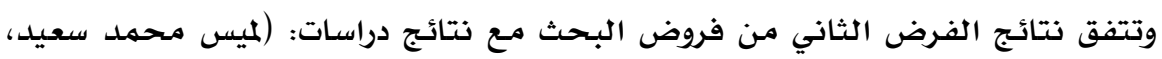

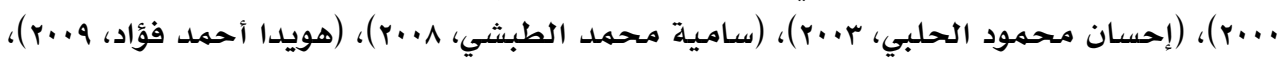

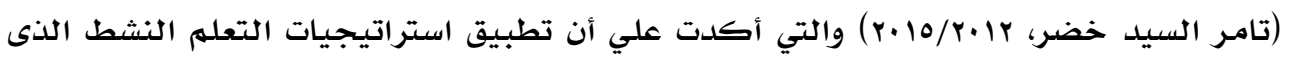

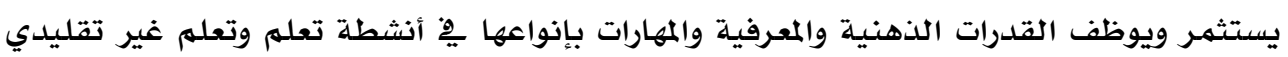

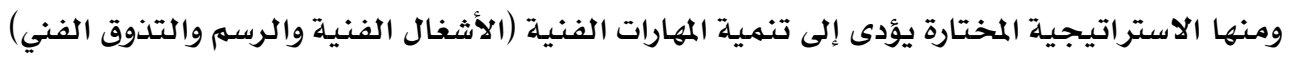

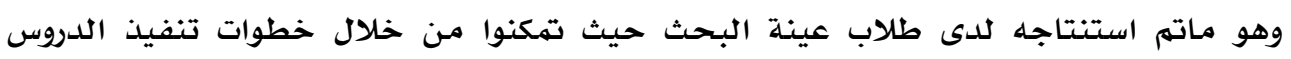

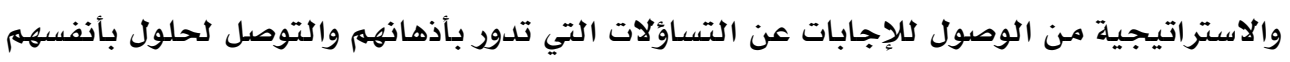

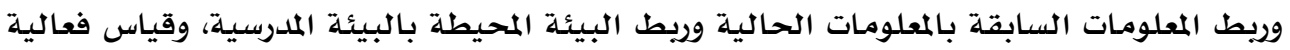


مجلة بحوث التربية النوعية - علدد •r.r. - م أكتوير

استخدام استراتيجية اليد المفكرة ِِّ تنمية الجوانب الأدائية للمهارات الفنية لدى الطلاب المعاقين بصريًا:

لقياس فعالية استخدام استراتيجية اليد المفكرة فِ تنمية الجوانب الأدائية للمهارات الفنية

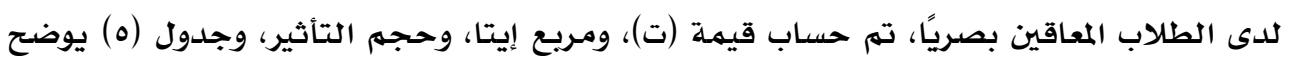

ذلك:

ثانيًا: حجم التأثير

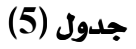

حجم تأثير استخدام استراتيجية اليد المفكرة فِ تنمية الجوانب الأدائية للمهارات الفنية لدى الطلاب المعاقين بصريًا

\begin{tabular}{|c|c|c|c|}
\hline حجم التأثير & مربع إيتا & قيمة (ت) & الأبعاد \\
\hline مرتفع & 99 & $09, \mathrm{rq}$ & is \\
\hline مرتفع & ,99 & $\{r, q \Lambda$ & $r_{P}$ \\
\hline مرتفع & , 99 & $\wedge ৭, \Sigma \vee$ & الكل \\
\hline
\end{tabular}

يتضح من جدول (ه) أن مريع إيتا لكل بعد من بعدي الجوانب الأدائية للمهارات الفنية

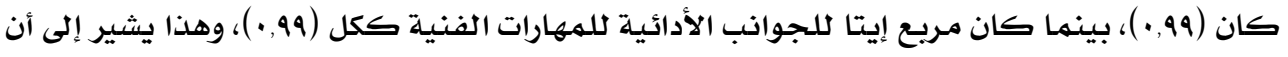

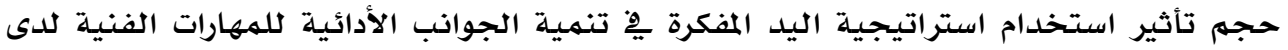

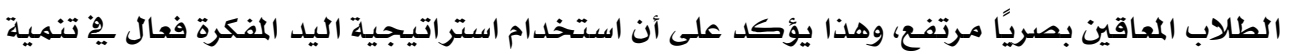

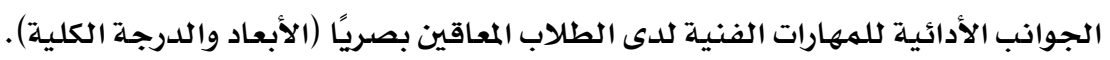

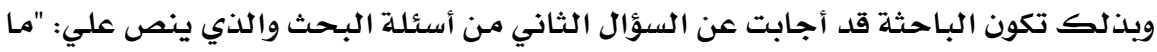

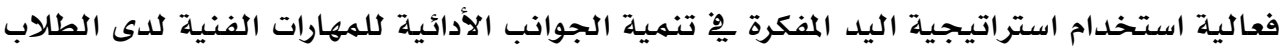

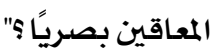

\section{توصيات البمث}

مِِْ ضوء نتائج الدراسـة الحالية توصى الباحثة بها يلي: • ضرورة تعديل وتطوير مناهج التربية الفنية للمكفوفين بالمراحل التعليمية المختلفة وخاصدة

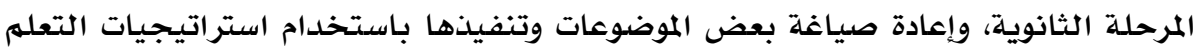

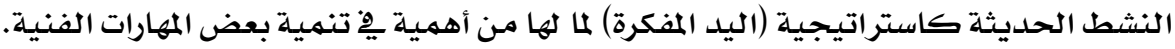

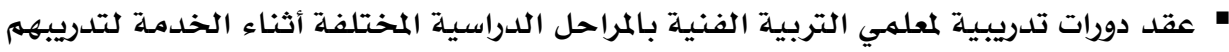
على الاستراتيجيات الحديثة كاستراتيجية (اليد المفكرة). 


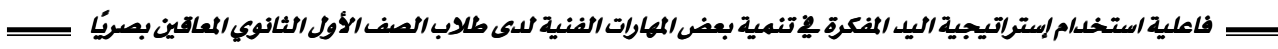

تبنى الإتجاه لتدريب الطلاب المكفوفين على مهارسلة المهارات الفنية من خلال الخبرة الحسيـة المباشرة باستخدام استراتيحية (اليد المفكرة) فِ مـراحل دراسية مختلفة ويخ مواد دراسية

أخرى.

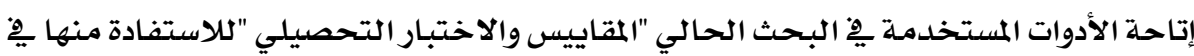
عمليات المتابعة والتقييهم فِ تدريس التربية الفنيـة.

زيادة عدد حصص التربية الفنية لما لها من أهمية أثناء الدراسلة حيث تساعد الطلبة على الإنتاج الفني مها يوفر فرصا للترفيه الإيجابي المنتجج.

\section{مقترحات لبحوث أخرى مِّ ضوء النتائج والتوصيات}

ا- راسـة تأثير تدريس التربية الفنية باستخدام استراتيجية اليد المفكرة لفئات أخرى مـن ذوي الاحتياجـات الخاصلة على تنهية المهارات الفنيىلة والتذوق الفني. ץ- راسـة تأثير تطبيق استراتيجية اليد المفكرة يِّ تدريس التربية الفنية للطلاب المعاقين بصريًا على بعض المهارات الحياتيـة واتخاذ القرار.

المراجع

أوثًا: المراجع العربية:

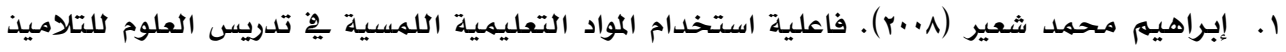
المعاقين بصريًا بالمرحلة الإبتدائية على كلًا من التحصيل وتنمية بعض عمليات العلم والدافع للانجاز. مجلة مركز رعاية وتنمية الطفولة, جامعة المنصورة.

r. إحسان محمود الحلبي (r..r). فاعلية استخدام بعض الوسائل التعليمية يخ تدريس وحدة الزخارف لطالبات المدرسه الثانوية الصناعية تخصص ملابس جاهزة مٍِ تنمية بعض مهارات الرسهم والتنفيذ والدافعية. المؤتمر العلمي السنوى الخامس عشر. كلية التربية، جامعة المنصوه , ع- ه ابريل. r. إيمان حسن حسن زغلول (rا.rr). أثر استخدام أنهاط الرسومات التعليمية البارزة والخبرة البصرية

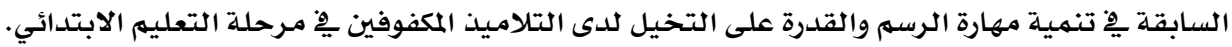
دراسات وبحوث, كلية التربية, قسم تكنولوجيا التعليم, حلوان.

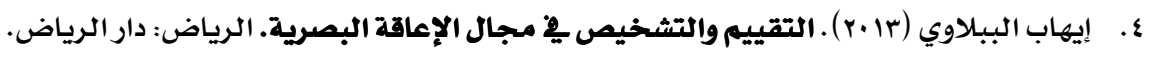

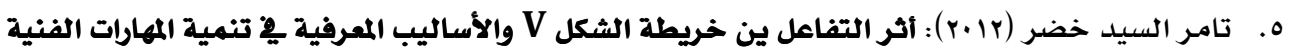
لدى تلاميذ المرحلة الاعدادية. رسالة ماجستير غير منشورة، كلية التربية النوعية، جامعة المنصورة.

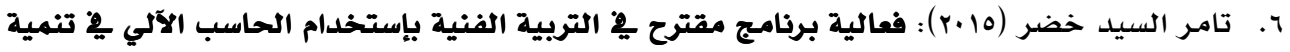
بعض المهارات الفنية والاتجاه نحو المادة لدى طلاب الصف الأول الثانوي. رسالة دكتوراه غير منشورة, كلية التربية النوعية، جامعة المنصورة. 
مجلة بحوث التربية النوعية - علد •r - r.r. أكتوبر

V. تامـر على عبداللطيف (17) (r). إستخدام إستراتيجية اليد المفكرة HANDS ON لتصويب بعض التصورات البديلة وتنمية بعض عمليات العله لدى تلاميذ المرحلة الإبتدائية بهنطقة الباحة. المجلة

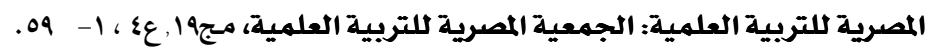
^. جيهان رجب عطا الله (11 +r). فعالية استراتيجية اليد المفكرة ـ2 تنمية التحصيل ومهارات حل المشكلات فو مادة العلوم للدي تلاميذ المرحلة الإعدادية. رسالة ماجستير غير منشورة, كلية التربية, جامعة

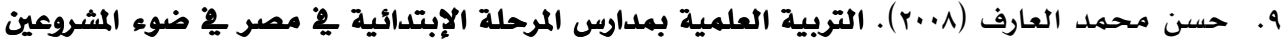
(الفرنسي والياباني), الجمعية المصرية للتربية العلمية, المؤتهر العلهي الثاني عشر, التربية العلمية والواقع المجتمعي: التأثير والتأثر .

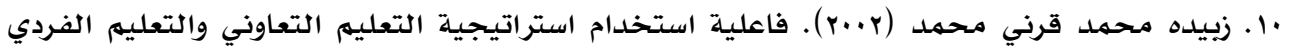
بإستخدام الكمبيوتر على التحصيل ٌِِ مادة العلوم وتنمية التفكير الإبتكارى لدى تلاميذ الصف الأول الإعدادي. مجلة التربية التعليمية, الجمعية المصرية للتربية العلمية, ور- 110 .

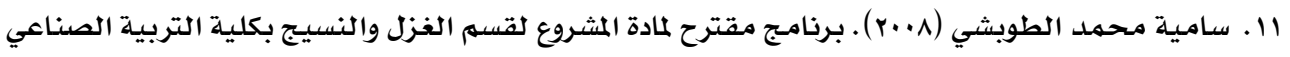
وقياس فاعليتها لتنمية مهارات واتجاهات الطلاب. المؤتمر العلمي الثالث, كلية التربية النوعية, جامعة المنصورة. •TVI

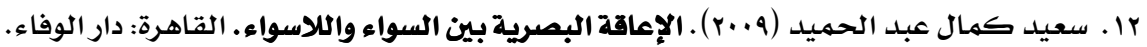

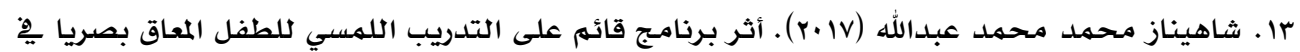
تنهية مفهوم الذات الأكاديهي : ع ا. عبد العزيز السيد الشخص (2006). مقياس المستوى الاجتماعي للأسرة. ط3. القاهرة: مكتبة الأنجلو المصرية. 10 . عبدالرازق مختار محمود، ومحمد صدلاح سيد، وأحمد محمد علي (·r.r). أثر إستخدام نموذج اليد المفكرة المدعوم بعملية المراجعة يْ علاج أخطاء الكتابة لدى تلاميذ الصف السادس الإبتدائي. المجلة

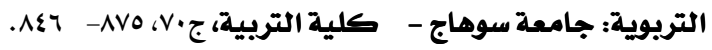

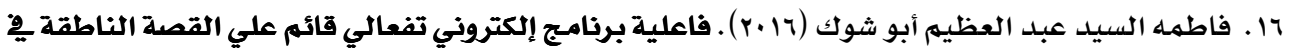
تنمية بعض المهارات السمعية للي للتلاميذ المكفوفين بالمرحلة الابتدائية. رسالة ماجستير غير منشورة. كلية التربية, جامعة عين شمس.

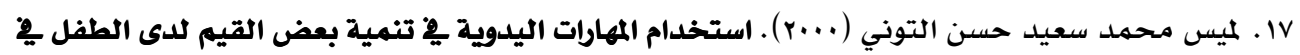
المرحلة الإبتدائية. رسالة ماجستير غير منشورة، كلية البنات, جامعة عين شمس. 1 ا. ماهر اسماعيل صبرى (19 •r). أثر الكتاب الصوتي الرقهي فى تتهىى مهارات التعبىر الشفوي باللغة الإنجلىزىقة لدى الطلاب المكفوفىن بالمرحلة الثانوىة. بحوث عربية يِّ مجالات التربية النوعية, العدد الثالث عشر, كلية التربية, بنها. 


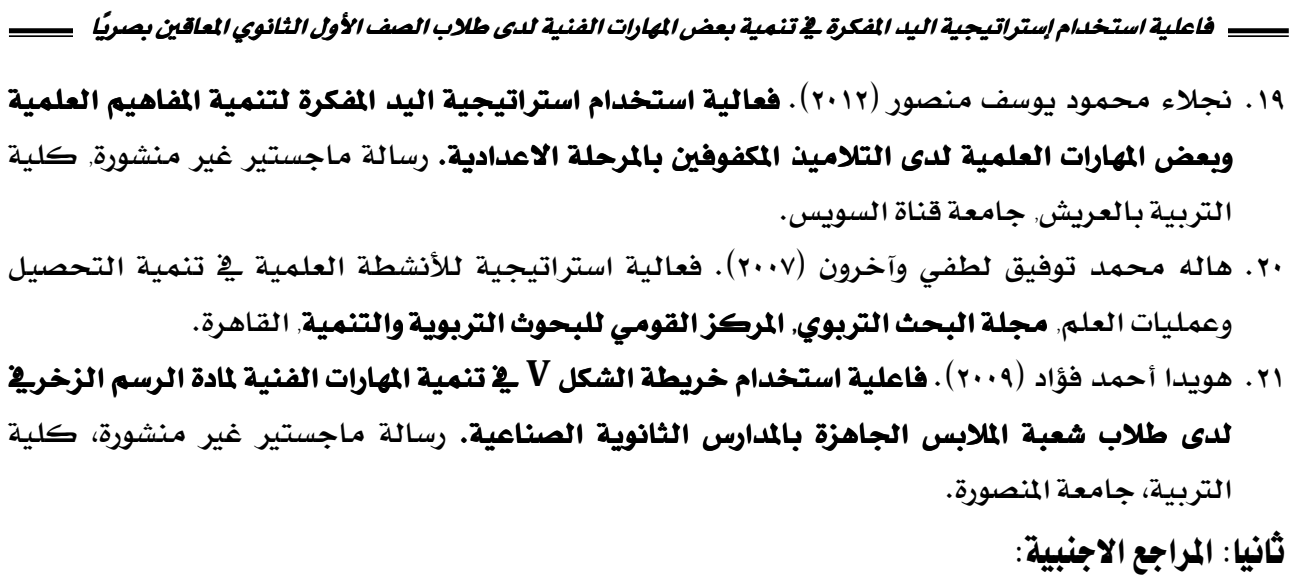

1. Al-Dababneh, K., Al-Masa'deh, M. and Oliemat, E.M., (2015) 'The effect of a training programme in creativity on developing the creative abilities among children with visual impairment.' Early Child Development and Care, 185(2), 317- 339.

2. Annie Penda (2018). The challenges in teaching learners: BMC Medicine,2(4),157-166.

3. Berger, J (2008). Ways of seeing, London: Penguin . British Educational Research Association (BERA).

4. Burton, J., Horowitz, R. and Abeles, H., (2000). 'Learning in and through the arts: The question of transfer.' Studies in art education, 41(3), 228-257.

5. Carroll, T. (1961) . Blindness: What It Is, What It Does, And How To Live With It Paperback - January 1, 1961 https://www.amazon.com/BlindnessWhat-Does-How-Live/dp/B0006AX7DG

6. Department of Education and Department of Health. (2015) Special educational needs and disability code of practice: to 25 years. Available at: https://www.gov.uk/government/uploads/system/uploads/attachment_data/file / 398815/SEND_Code_of_Practice_January_2015.pdf (Accessed: 20th September 2017).

7. Dissanayake, E., (2015) What is art for?, 5th edn., Seattle: University of Washington Press. United Kingdom. Education Act (1981) Chapter 60, Available at: http://www.legislation.gov.uk/ukpga/1981/60/enacted (Accessed: 20th September 2017).

8. Ediger,M. (2005). How to generate student excitement in science. Science Activites: Classrom Projects and Curriculum Ideas. ERIC,41(4),15-17. 
مجلة بحوث التربية النوعية- علدد •r.r.r. - م أكتوبر

9. Fiskke, E. (1999). Champions of Change: The Impact of the Arts on Learning. President's Committee on the Arts and the Humanities, Washington, DC.; Arts Education Partnership, Washington, DC. Available at: https://eric.ed.gov/?id=ED435581 (Accessed: September 24th 2017).

10. Hetland, L. (2015). Studio thinking 2: The real benefits of visual arts education., 2nd edn., New York: Teachers College Press and The National Art Education Association.

11. Jorquenson, O (2005). What K-6 principals Should know about hand-on. Principals, 85(2),49-52.

12. Kate Phoenix (2018). The Value of Visual Art Education for Pupils with Visual Impairment A BEd 4 Capstone Project Submitted in Partial Fulfilment of the Requirements for the Degree of Bachelor of Education (Hons) in Art and Design by St Mary's University College Belfast January.

13. Lalit Dandona (2006). Revision of visual impairment definitions in the International Statistical Classification of Diseases. BMC Medicine. 4,

14. Milne and Ladner, et al. (2018). HI '18: Proceedings of the CHI Conference on Human Factors in Computing Systems. 